\title{
PONDERAÇÃO BAYESIANA DE MODELOS EM REGRESSÃO LINEAR CLÁSSICA
}

\author{
HÉlio Rubens De CARVAlho Nunes
}

\begin{abstract}
Dissertação apresentada à Escola Superior de Agricultura "Luiz de Queiroz", Universidade de São Paulo, para obtenção do título de Mestre em Agronomia, Área de Concentração: Estatística e Experimentação Agronômica.
\end{abstract}

P I R A C I C A B A

Estado de São Paulo - Brasil

Agosto - 2005 


\title{
PONDERAÇÃO BAYESIANA DE MODELOS EM REGRESSÃO LINEAR CLÁSSICA
}

\author{
Hélio Rubens De Carvalho Nunes
}

Bacharel em Estatística

Orientadora: $\operatorname{Prof}^{\underline{a}} \operatorname{Dr}^{\underline{a}}$ ROSELI APARECIDA LEANDRO

Dissertação apresentada à Escola Superior de Agricultura "Luiz de Queiroz", Universidade de São Paulo, para obtenção do título de Mestre em Agronomia, Área de Concentração: Estatística e Experimentação Agronômica.

P I R A C I C A B A

Estado de São Paulo - Brasil

Agosto - 2005 
Dados Internacionais de Catalogação na Publicação (CIP) DIVISÃO DE BIBLIOTECA E DOCUMENTAÇÃO - ESALQ/USP

Nunes, Hélio Rubens de Carvalho

Ponderação bayesiana de modelos em regressão linear clássica / Hélio Rubens de Carvalho Nunes. - - Piracicaba, 2005.

$54 \mathrm{p}$.

Dissertação (Mestrado) - - Escola Superior de Agricultura Luiz de Queiroz, 2005.

Bibliografia.

1. Análise de regressão 2. Inferência bayesiana I. Título

CDD 519.536

"Permitida a cópia total ou parcial deste documento, desde que citada a fonte - O autor" 


\section{DEDICATÓRIA}

Aos meus pais,

\section{Waldir Nunes e Maria Magdalena de Carvalho Nunes.}

Todos esses anos dedicados à minha educação e formação certamente mereciam muito mais que essas humildes palavras. Nunca me esquecerei das orientações e conselhos nos momentos difíceis, dos risos compartilhados em ocasiões festivas e principalmente do amor que cada um a seu modo sente por mim. Que este pequeno trecho consiga transmitir o amor que sinto por vocês!

À minha esposa,

\section{Paula Roberta Mendes.}

A amizade, o respeito e a compreensão sempre foram marcantes em nosso relacionamento. 


\section{AGRADECIMENTOS}

À Prof ${ }^{\underline{a}}$ Dr $\stackrel{a}{a}$ Roseli Aparecida Leandro pela orientação. Sua conduta sempre firme e sincera me fez enxergar os requisitos que a vida acadêmica exige de um profissional. Foram dois anos e meio de muito aprendizado e observação. Vou sentir saudades!

À Prof ${ }^{\underline{a}}$ Dr ${ }^{\underline{a}}$ Clarice Garcia Borges Demétrio pela capacidade de liderança, vocação para o ensino e por saber aconselhar e cobrar nos momentos mais adequados. Buscarei sempre a objetividade!

Ao Prof ${ }^{o}$ Dro ${ }^{o}$ Edwin Moisés Marcos Ortega pela amizade e apoio.

À Prof ${ }^{\underline{a}} \operatorname{Dr}^{\underline{a}}$ Cecília Candolo da Universidade Federal de São Carlos pela troca de informação acerca do tema deste trabalho.

Ao Prof ${ }^{o}$ Dro ${ }^{-}$Sílvio Sandoval Zocchi. Por ter me apoiado em períodos complicados.

Ao pesquisador Bill Venables, do CSIRO, Cleveland, Austrália.

Ao pesquisador Antonio de Oliveira Lobão, do CESAHO, Piracicaba.

À Solange de Assis Paes Sabadin pela disposição sincera e pela eficiência com que cuidou dos assuntos extra-classe.

À Luciane Brajão pelo atendimento sempre simpático.

A Jorge Alexandre Wiendl pelo apoio técnico.

Aos amigos do mestrado: Alfredo, Édila, Elisabeth, Francine, Juliana, Ana, Júlio, Lúcio, Melissa, Moita, Sandra e William.

Aos amigos do doutorado: Afrânio, Ana, Andréia, David, Denise, Elizabeth, Fogo, Giovana, Genevile, Idemauro, João Maurício, Luciana, Luciano, Osmar e Pedro.

Aos professores da DEs/UFSCar.

Aos membros dos grupos "GDP-1"e "Agronomia" do CESAHO.

Ao CNPQ e à CAPES pelo apoio financeiro. 


\section{SUMÁRIO}

Página

LISTA DE FIGURAS . . . . . . . . . . . . . . . . . . . . . vi vi

LISTA DE TABELAS . . . . . . . . . . . . . . . . . . . vii

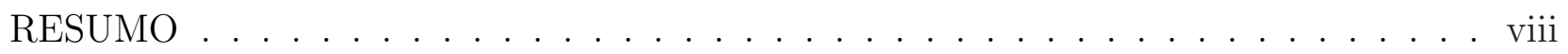

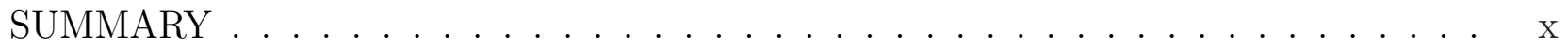

$1 \quad$ INTRODUÇÃ $\ldots \ldots \ldots \ldots \ldots \ldots \ldots$

2 REVISÃO DE LITERATURA . . . . . . . . . . . . . . . . . . . . 3

2.1 A seleção de modelos em regressão linear clássica . . . . . . . . . . . . . . 3

2.2 A incerteza envolvida no processo de seleção de modelos . . . . . . . . . . . 7

2.3 A ponderação de modelos . . . . . . . . . . . . . . . 8

2.3.1 A ponderação Bayesiana de modelos . . . . . . . . . . . . . . . . 10

2.3.2 Desempenho preditivo da ponderação Bayesiana de modelos . . . . . . . . . . 12

3 MATERIAL E MÉTODOS . . . . . . . . . . . . . . . . . . 14

$3.1 \quad$ Material . . . . . . . . . . . . . . . . . . . 14

3.1 Para a aplicação da metodologia BMA . . . . . . . . . . . . . . . 15

3.1.2 Para a avaliação do desempenho preditivo do BMA . . . . . . . . . . . . . . . 19

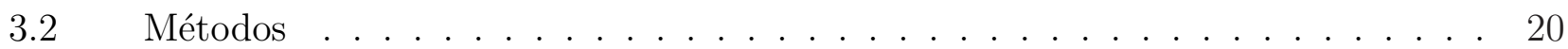

3.2.1 Ponderação Bayesiana de modelos de regressão linear clássica . . . . . . . . . . 20

4 RESULTADOS E DISCUSSÃO . . . . . . . . . . . . . . . 29

$4.1 \quad$ Estudo de Simulação . . . . . . . . . . . . . . . . . . . . . . 36

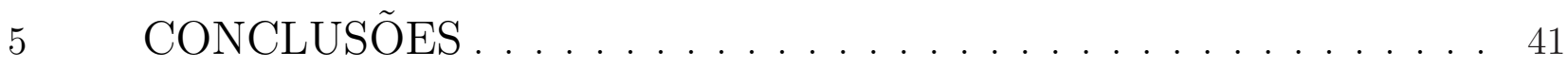

REFERÊNCIAS BIBLIOGRÁFICAS . . . . . . . . . . . . . . 42

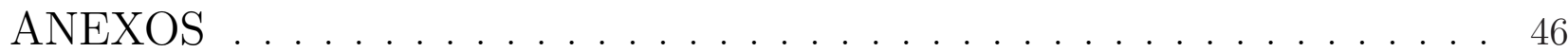




\section{LISTA DE FIGURAS}

Página

1 Processo de seleção de modelos . . . . . . . . . . . . . . . . . 7

2 Distribuições a priori para $\sigma^{2}$ segundo valores de $\nu$ e $\lambda \ldots \ldots$. . . . . . . . 24

3 Boxplot para o número de condição das amostras simuladas para cada combinação entre cultivar e tamanho amostral . . . . . . . . . . . . . . . 37

4 Comportamento da média do Logaritmo do Escore Preditivo da metodologia BMA (vermelho) e dos critérios: $R^{2}$ (preto), $\bar{R}^{2}$ (preto tracejado), PRESS (azul) e $C_{p}$ (azul Tracejado) . . . . . . . . . . . . . . . . . . . 40 


\section{LISTA DE TABELAS}

Página

1 Dados referentes ao cultivar C-111, Paraná, $1976 \ldots \ldots$. . . . . . . . . 16

2 Dados referentes ao cultivar Piranão, Paraná, 1976 . . . . . . . . . . . . . 17

3 Dados referentes ao cultivar Flint Composto, Paraná, 1976 . . . . . . . . . . . . 18

4 Ilustração de um específico conjunto de dados simulado . . . . . . . . . . . . . . . 20

5 Opções para os valores dos hiperparâmetros . . . . . . . . . . . . . . . . . . 22

6 Estimativas de mínimos quadrados dos coeficientes de regressão dos modelos selecionados através do critério $\bar{R}^{2}$ - Cultivar C-111 . . . . . . . . . . . . . 30

7 Estimativas de mínimos quadrados dos coeficientes de regressão dos modelos selecionados através do critério $\bar{R}^{2}$ - Cultivar Piranão . . . . . . . . . . . . . . . 31

8 Estimativas de mínimos quadrados dos coeficientes de regressão dos modelos selecionados através do critério $\bar{R}^{2}$ - Cultivar Flint Composto . . . . . . . . . . . . . 31

9 Análises clássica e Bayesiana dos dados do cultivar Flint Composto . . . . . . . . 33

10 Modelos selecionados pelo Occam's Window simétrico, executado com diferentes

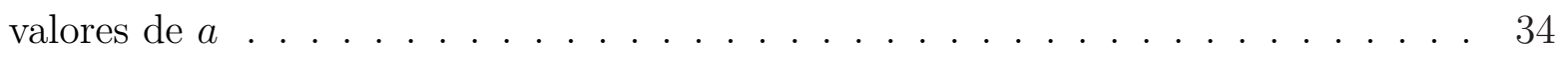

11 Esperança e variância a posteriori de cada coeficiente obtida pela ponderação dos modelos selecionados pelo OW para cada valor de $a \ldots \ldots$. . . . . . . . 35

12 Resumo descritivo para o número de condição $\left(k^{*}\right)$ das amostras geradas para cada combinação tamanho amostral e cultivar . . . . . . . . . . . . . . . . 37

13 Resumo dos valores do LEP nas amostras simuladas (cultivar C-111) . . . . . . 38

14 Resumo dos valores do LEP nas amostras simuladas (cultivar Piranão) . . . . . 39

15 Resumo dos valores do LEP nas amostras simuladas (cultivar Flint Composto) . . 39 


\title{
PONDERAÇÃO BAYESIANA DE MODELOS EM REGRESSÃO LINEAR CLÁSSICA
}

\author{
Autor: HÉLIO Rubens De CARVAlHo NuneS \\ Orientadora: $\operatorname{Prof}^{\underline{a}} \operatorname{Dr}^{\underline{a}} \underline{\text { ROSELI APARECIDA LEANDRO }}$
}

\section{RESUMO}

Este trabalho tem o objetivo de divulgar a metodologia de ponderação de modelos ou Bayesian Model Averaging (BMA) entre os pesquisadores da área agronômica e discutir suas vantagens e limitações. Com o BMA é possível combinar resultados de diferentes modelos acerca de determinada quantidade de interesse, com isso, o BMA apresenta-se como sendo uma metodologia alternativa de análise de dados frente os usuais métodos de seleção de modelos tais como o Coeficiente de Determinação Múltipla $\left(R^{2}\right)$, Coeficiente de Determinação Múltipla Ajustado $\left(\bar{R}^{2}\right)$, Estatística de Mallows $\left(C_{p}\right)$ e Soma de Quadrados de Predição (PRESS). Vários trabalhos foram, recentemente, realizados com o objetivo de comparar o desempenho do BMA em relação aos métodos de seleção de modelos, porém, há ainda muitas situações para serem exploradas até que se possa chegar a uma conclusão geral acerca desta metodologia. Neste trabalho, o BMA foi aplicado a um conjunto de dados proveniente de um experimento agronômico. A seguir, o desempenho preditivo do BMA foi comparado com o desempenho dos métodos de seleção acima citados por meio de um estudo de simulação variando o grau de multicolinearidade e o tamanho amostral. Em cada uma dessas situações, foram utilizadas 1000 amostras geradas a partir de medidas descritivas de conjuntos de dados 
reais da área agronômica. O desempenho preditivo das metodologias em comparação foi medido pelo Logaritmo do Escore Preditivo (LEP). Os resultados empíricos obtidos indicaram que o BMA apresenta desempenho semelhante aos métodos usuais de seleção de modelos nas situações de multicolinearidade exploradas neste trabalho. 


\title{
BAYESIAN MODEL AVERAGING IN CLASSIC LINEAR REGRESSION MODELS
}

\author{
Author: HÉlio RuBENS DE CARVALHO NunES \\ Adviser: Prof $\underline{\underline{a}}$ Dr$\underline{\underline{a}}$ ROSELI APARECIDA LEANDRO
}

\section{SUMMARY}

The objective of this work was divulge to Bayesian Model Averaging (BMA) between the researchers of the agronomy area and discuss its advantages and limitations. With the BMA is possible combine results of different models about determined quantity of interest, with that, the BMA presents as being a metodology alternative of data analysis front the usual models selection approaches, for example the Coefficient of Multiple Determination $\left(R^{2}\right)$, Coefficient of Multiple Determination Adjusted $\left(\bar{R}^{2}\right)$, Mallows $\left(C_{p}\right.$ Statistics $)$ and Prediction Error Sum Squares (PRESS). Several works recently were carried out with the objective of compare the performance of the BMA regarding the approaches of models selection, however, there is still many situations for will be exploited to that can arrive to a general conclusion about this metodology. In this work, the BMA was applied to data originating from an agronomy experiment. It follow, the predictive performance of the BMA was compared with the performance of the approaches of selection above cited by means of a study of simulation varying the degree of multicollinearity, measured by the number of condition of the matrix standardized $\mathbf{X}^{\prime} \mathbf{X}$ and the number of observations in the sample. In each one of those situations, were utilized 1000 samples generated from the descriptive information of agronomy data. The predictive performance of the metodologies in comparison was 
measured by the Logarithm of the Score Predictive (LEP). The empirical results obtained indicated that the BMA presents similar performance to the usual approaches of selection of models in the situations of multicollinearity exploited. 


\section{INTRODUÇÃO}

Métodos de seleção de modelos (ou variáveis) são freqüentemente utilizados em trabalhos que envolvem modelagem estatística porque geralmente, nesses trabalhos, há uma disposição natural por parte do pesquisador em observar uma grande quantidade de variáveis na expectativa de que ao serem incluídas em um modelo estatístico, este ajuste-se aos dados amostrais da melhor forma possível.

Porém, sem um bom conhecimento teórico acerca do fenômeno em estudo, a observação de muitas variáveis pode trazer o problema da multicolinearidade, ou seja, algumas das variáveis observadas podem ser altamente correlacionadas. A multicolinearidade faz com que algumas das variáveis sejam irrelavantes para a explicação do fenômeno em estudo, além disso, a inclusão dessas variáveis em um modelo aumenta a variância dos estimadores de mínimos quadrados de seus coeficientes de regressão (Rao, 1971). Além dos problemas de estimação, modelos superparametrizados podem ser incovenientes do ponto de vista prático para seu usuário que pode ser: um pesquisador; um instituto de pesquisa ou uma empresa. Por outro lado, a omissão de variáveis importantes em um modelo introduz vício nos mesmos estimadores de mínimos quadrados, além disso, modelos subparametrizados podem não representar adequadamente o fenômeno em estudo.

Por essas e outras razões é que os métodos de seleção de modelos são tão utilizados. Espera-se que o modelo selecionado contorne os problemas trazidos pela sub ou superparametrização da melhor maneira possível.

Entretanto, a utilização de métodos de seleção normalmente condiciona as conclusões e tomadas de decisão do pesquisador a um único modelo, descartando com isso a possibilidade de outros modelos que se ajustam razoavelmente bem aos dados serem levados em consideração. Em algumas situações talvez existam razões científicas que justifiquem a adoção de um único modelo, mas em muitas outras, como por exemplo em regressão linear múltipla com muitas variáveis, muitos modelos podem se ajustar igualmente bem aos dados, 
explicando-os de forma plausível e fornecendo estimativas substancialmente distintas de um mesmo coeficiente de regressão.

Situações como esta pode provocar um certo desconforto e uma sensação de incerteza no(s) responsável(eis) pela escolha do modelo, pois pequenas diferenças nas estimativas de um coeficiente podem representar, na realidade, grandes diferenças orçamentárias ou mudanças significativas das estratégias de um instituto de pesquisa/empresa privada.

A incerteza diante da escolha de um modelo pode ser contornada por meio de uma combinação ponderada entre todos os modelos propostos ao ajuste dos dados ou apenas entre os melhores modelos, indicados com o auxílio de algum critério. Esta combinação pode ser feita seguindo os princípios da estatística clássica ou Bayesiana. Sob os princípios da estatística Bayesiana esta combinação é conhecida por ponderção Bayesiana de modelos ou Bayesian Model Averaging (BMA) (Leamer, 1978). O BMA é essencialmente a sistematização do conceito de se concluir e tomar decisões com base em uma combinação de resultados obtidos sob diferentes modelos.

A partir da década de 1990, vários trabalhos acerca do BMA foram realizados com o objetivo de compará-lo com os métodos de seleção de modelos, no entanto, há ainda muitas situações para serem exploradas até que se possa chegar a uma conclusão geral acerca desta metodologia.

O BMA é aplicável em diversas classes de modelos. Atualmente, apenas em regressão linear clássica os seus termos podem ser obtidos de forma analítica exata sem a necessidade de recorrer a métodos de aproximação. Além da combinação de informações acerca de coeficientes de regressão e de predições da variável resposta, o BMA também pode ser utilizado para contornar a incerteza diante da escolha da transformação mais adequada a um conjunto de dados ou para identificação de outliers.

Muitas sugestões de pesquisa acerca do BMA foram propostas em trabalhos recentes, como por exemplo o estudo das vantagens em implementá-lo para ponderar modelos pertencentes a diferentes classes e o desenvolvimento de formas analíticas exatas dos seus termos.

O presente trabalho apresenta a metodologia BMA e tem por objetivo divulgá-la entre os pesquisadores da área agronômica. Através da sua aplicação, pretende-se discutir suas vantagens e desvantagens em relação aos procedimentos de seleção de modelos normalmente utilizados e avaliar seu desempenho preditivo na classe dos modelos de regressão linear clássica. 


\section{REVISÃO DE LITERATURA}

Nesta seção, apresenta-se um breve histórico acerca da seleção de modelos em regressão linear clássica e uma das possíveis formas de caracterização da incerteza diante da escolha de um modelo.

\subsection{A seleção de modelos em regressão linear clássica}

A análise de regressão linear é uma técnica estatística muito utilizada em várias áreas de pesquisa. Com ela o pesquisador pode investigar a possível existência de uma relação entre as variáveis observadas durante seu estudo. Esta relação é representada, matematicamente, por uma equação (ou modelo) entre a variável resposta $Y$ (a de maior interesse no estudo) e $p$ variáveis $X_{1}, \ldots, X_{p}$ que supostamente explicam a variabilidade de $Y$. A forma desta equação para cada uma das $n$ observações da amostra é:

$$
Y_{i}=\beta_{0}+\sum_{j=1}^{p} \beta_{j} X_{i j}+\varepsilon_{i}, \quad i=1, \ldots, n,
$$

podendo $\beta_{0}, \beta_{1}, \ldots, \beta_{p}$ serem estimados pelo método dos mínimos quadrados. $\mathrm{O}$ termo $\varepsilon_{i}$ representa a influência do acaso sobre o valor de $Y_{i}$.

O conhecimento teórico do pesquisador sobre o fenômeno em estudo e as investigações exploratórias sobre os dados amostrais podem sugerir que sejam acrescentadas na expressão (1) algumas interações ou funções das variáveis explicativas.

Sempre que possível o pesquisador tende a observar muitas variáveis explicativas na expectativa de conseguir controlar grande parte da variabilidade de $Y$, entretanto, a inclusão de todas essas variáveis no modelo geralmente contraria o princípio da parcimônia ${ }^{1}$, além de superestimar (overfitting) o modelo. Por essa razão, recomenda-se que sejam incluídas no modelo apenas as variáveis mais relevantes.

\footnotetext{
${ }^{1}$ Criada por William de Ockham por volta de 1315, o princípio da parcimônia diz que, dentre várias hipóteses que explicam um acontecimento, a mais plausível é quase sempre a mais simples.
} 
Segundo Neter et al. (1983), a seleção de variáveis (ou de modelos) é uma das questões mais importantes de uma análise de regressão linear. Neste trabalho esta questão é discutida levando-se em conta apenas modelos cuja forma é dada por (1), restringindo a discussão a um conjunto de exatamente $\sum_{r=0}^{p}\left(\begin{array}{l}p \\ r\end{array}\right)=2^{p}$ modelos, dos quais, $\left(\begin{array}{l}p \\ r\end{array}\right)$ possuem $r$ das $p$ variáveis observadas.

O processo de seleção de modelos é uma das partes que compõe toda a questão da seleção de modelos. Este processo pode ser realizado de duas formas: ajustando todos os possíveis modelos e comparando-os por meio de um critério pré-estabelecido ou automaticamente através de métodos do tipo Stepwise, por exemplo. No primeiro caso, os ajustes de cada modelo são avaliados, e o modelo que apresentar o melhor desempenho conforme o critério estabelecido é então escolhido para representar os dados amostrais. No segundo caso, o processo de seleção é executado por passos, sendo que, em cada passo, uma variável explicativa pode ser incluída ou excluída do conjunto das mais relevantes de acordo com o resultado de uma estatística pré-determinada. No fim da execução do método, as variáveis consideradas mais relevantes deverão compor um modelo que, conseqüentemente, será considerado o melhor. Tais métodos baseiam-se nos princípios conhecidos por Seleção Forward e Eliminação Backward, como por exemplo, a Regressão Stepwise (Efroymson, 1960). Portanto, o processo de seleção é o meio operacional pelo qual o modelo que melhor representa as observações amostrais é identificado. O desempenho e a escolha deste processo pode ser influenciado de forma direta ou indireta por vários fatores, entre eles os interesses do pesquisador pelo modelo, o enfoque adotado na análise (Bayesiano ou freqüentista), as possíveis falhas de especificação do modelo (misspecification) etc.

Vários critérios são freqüentemente utilizados nos processos de seleção de modelos de regressão linear, sendo a estatística da Razão de Verossimilhança o principal deles, no entanto, quando modelos aninhados são comparados e quando o comportamento assintótico é válido, a Razão de Verossimilhança torna-se inconsistente, tendendo a favorecer o modelo completo (Gelfand \& Ghosh, 1998). Para evitar tal favorecimento, foram criados critérios que penalizam os modelos que possuem muitas variáveis. Alguns desses critérios são: a Deviance (Nelder \& Wedderburn, 1972); o critério de informação de Akaike (Akaike, 1973) e o critério de informação de Bayes (Schwarz, 1978). Há, também, critérios diretamente baseados na soma de quadrados residual (SQRes), sendo que os mais utilizados na estatística aplicada, conforme Hocking (1976) são: 
O quadrado médio residual,

$$
Q M \operatorname{Res}_{p}=\frac{S Q R e s_{p}}{n-p} .
$$

O coeficiente de determinação,

$$
R_{p}^{2}=1-\frac{S Q R e s_{p}}{S Q T o t a l} .
$$

O coeficiente de determinação ajustado,

$$
\bar{R}_{p}^{2}=1-\frac{(n-1)}{(n-p)}\left(1-R_{p}^{2}\right) .
$$

A variância de predição média,

$$
J_{p}=\frac{(n+p)}{n} Q M \operatorname{Res}_{p} .
$$

O erro quadrático total,

$$
C_{p}=\frac{S Q R e s_{p}}{\widehat{\sigma}^{2}}+2 p-n .
$$

A soma de quadrados de predição,

$$
P R E S S_{p}=\mathbf{e}_{p}^{\prime} \mathbf{D}_{p}^{-1} \mathbf{e}_{p}
$$

sendo $\mathbf{e}_{p}=\mathbf{y}-\widehat{\mathbf{y}}_{p}$ e $\left.\mathbf{D}_{p}=\operatorname{diag}\left(\mathbf{I}-\mathbf{X}_{p}\left(\mathbf{X}_{p}^{\prime} \mathbf{X}_{p}\right)\right)^{-1} \mathbf{X}_{p}^{\prime}\right)$.

Alguns desses critérios são mais adequados para determinados objetivos e não há uma regra definida sobre qual deles utilizar em cada situação. Uma ampla revisão sobre o assunto pode ser encontrada em Hocking (1976). Segundo o autor, tanto o $R_{p}^{2}$ como o $\bar{R}_{p}^{2}$ são muito utilizados quando o pesquisador quer descrever os dados amostrais resumindo as informações de um banco de dados por meio de um modelo. Quando o objetivo é a predição de um valor futuro de $Y$ ou do seu valor médio, Wetherill et al. (1986) sugerem os critérios $C_{p}$ e PRESS $S_{p}$. No entanto, se o objetivo for o controle de um determinado processo (situações nas quais busca-se determinar o intervalo de variação de uma variável explicativa que leve a desejáveis mudanças em $Y$ ), Chatterjee \& Price (1977) sugerem modelos que apresentam pequenas estimativas dos erros padrão associadas aos estimadores dos coeficientes inclusos na equação do modelo.

Historicamente, o processo de seleção de modelos foi pouco discutido até o fim da década de 1940, quando surgiram as primeiras calculadoras manuais. Na década de 
1950, trabalhos como os de Snedecor (1956) e Lyle (1957) trataram do assunto considerando situações onde apenas três ou quatro variáveis explicativas são observadas.

Somente a partir da utilização dos computadores, no final dessa mesma década, é que o processo de seleção começou a se desenvolver de forma efetiva. Foram criados algoritmos capazes de ajustar automaticamente grandes quantidades de modelos, como por exemplo, os algoritmos de Garside (1965), Newton \& Spurrel (1967) e de Furnival (1971). Todos esses algoritmos geram todas as $2^{p}$ combinações de modelos baseados no "Operador Sweep" (Beaton, 1964), exceto o algoritmo de Newton \& Spurrel (1967), que utiliza "elementos básicos"presentes na soma de quadrados de regressão de todos os modelos.

Assim como esses algoritmos, os processos de seleção do tipo Stepwise foram criados com o objetivo de permitir que o pesquisador identifique o melhor modelo sem que para isso tenha de ajustar todos os $2^{p}$ modelos.

Uma das vantagens desses algoritmos em relação aos critérios de seleção é a redução dos cálculos necessários para a obtenção de um modelo considerado o melhor, no entanto, como apenas uma parcela da totalidade dos $2^{p}$ modelos são avaliados, não se pode afirmar que o modelo obtido seja realmente o melhor dentre todos, pois no decorrer da execução, a procura pode seguir por uma direção na qual a melhor combinação de variáveis não foi considerada. Para contornar este problema, foram criados os algoritmos de procura otimizada, como por exemplo, o "Leaps and Bounds"(Furnival \& Wilson, 1974). Atualmente vários desses algoritmos encontram-se implementados em softwares tais como o $S A S$ (Statistical Analysis Sistem), S-Plus, Statistica, $R$ entre outros.

Do ponto de vista Bayesiano, o processo de seleção de modelos é conceitualmente simples (Laud \& Ibrahim, 1996 e Lee III, 1999). Seja $M_{k}, k=1, \ldots, 2^{p}$ um modelo com probabilidade a priori $P\left(M_{k}\right)$ e vetor de parâmetros $\boldsymbol{\theta}_{\boldsymbol{k}}$ com distribuição a priori $\pi\left(\boldsymbol{\theta}_{\boldsymbol{k}} \mid M_{k}\right)$ e função de verossimilhança $L\left(\boldsymbol{\theta}_{\boldsymbol{k}} ; \mathbf{y}\right)$. A função de verossimilhança marginal correspondente ao modelo $M_{k}$, é dada por:

$$
L_{k}(\mathbf{y})=\int \ldots \int L\left(\boldsymbol{\theta}_{\boldsymbol{k}} ; \mathbf{y}\right) \pi\left(\boldsymbol{\theta}_{\boldsymbol{k}} \mid M_{k}\right) d \boldsymbol{\theta}_{\boldsymbol{k}}
$$

Aplicando o teorema de Bayes, pode-se obter a probabilidade de $M_{k}$, condicionada a ocorrência da amostra $\mathbf{y}$ :

$$
P\left(M_{k} \mid \mathbf{y}\right)=\frac{L_{k}(\mathbf{y}) P\left(M_{k}\right)}{\sum_{l=1}^{2^{p}} L_{l}(\mathbf{y}) P\left(M_{l}\right)}, \quad k=1, \ldots, 2^{p} .
$$

Com isso, basta selecionar o modelo que tiver a maior probabilidade condi- 
cionada dada por (3).

\subsection{A incerteza envolvida no processo de seleção de modelos}

Segundo Tversky (1974), a incerteza é um elemento essencial da condição humana. Com base nesta afirmação, pode-se dizer que a incerteza está presente em quase todas as situações nas quais decisões precisam ser tomadas, como por exemplo nos processos de seleção de modelos. Nesse caso, a incerteza se caracteriza e mostra-se relevante quando em cada modelo são observadas diferentes estimativas e erros padrão de um mesmo coeficiente de regressão. Mesmo que resultados empíricos não indiquem diferenças estatisticamente significativas, as mesmas podem representar na prática diferenças significativas de orçamento, de políticas a serem adotadas etc.

Um processo de seleção de modelos pode ser visto como uma metodologia que tem por objetivo identificar modelos que combinem de forma satisfatória dois fatores: qualidade de ajuste aos dados e conseqüências gerenciais causadas pela sua escolha. O primeiro destes fatores é medido, numericamente, conforme o critério de seleção pré-estabelecido e por isso contribui menos para a geração da incerteza diante da escolha de um modelo do que o segundo fator, que tem caráter mais subjetivo, já que as regras para se decidir por um modelo muitas vezes não são tão claras. A incerteza envolvida nos processos de seleção se deve mais às razões subjetivas de uma tomada de decisão.

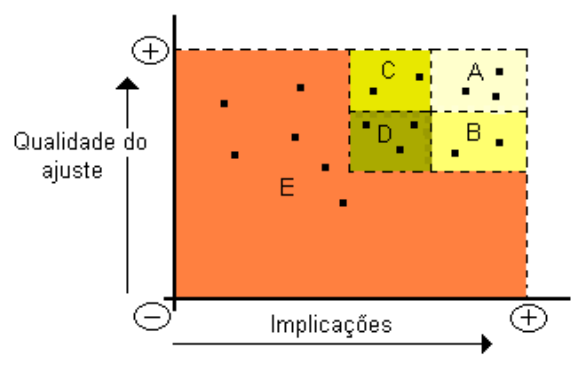

Figura 1 - Processo de seleção de modelos

Como ilustração, suponha que, em um experimento, quatro variáveis explicativas sejam observadas, possibilitando o ajuste de $2^{4}$ modelos e que o resultado da combinação dos fatores acima citados em cada modelo esteja representado pelos pontos da Figura 1. 
Verifica-se que os modelos da região A ajustam-se muito bem aos dados e, além disso, as consequiências práticas, econômicas e políticas devido a escolha de um modelo pertencente a essa região serão as melhores possíves. Já os modelos da região B apresentam um desempenho inferior em termos do critério de seleção utilizado, entretanto, as conseqüências da escolha de um modelo dessa região são as mesmas observadas na região A. Nas regiões C e D estão os modelos caros, de difícil manutenção e causadores de mudanças mais significativas na política e nas estratégias de uma empresa/instituto de pesquisa. Finalmente, na região E, encontram-se os modelos que não atingem níveis desejáveis em pelo menos um dos fatores, sendo portanto, desaconselhável a adoção de qualquer um desses para a representação dos dados amostrais.

As áreas A, B, C e D são regiões de incerteza nas quais o pesquisador não consegue identificar, dentro de cada uma delas, o modelo que produz a melhor combinação entre os fatores já citados, ou seja, há diferenças significativas entre as regiões, o que não ocorre entre os modelos dentro das mesmas. Essas regiões podem, dependendo da situação, reagruparem-se, formando novas regiões ou até mesmo uma única região de incerteza diante da escolha convicta de um modelo que possa ser considerado o gerador dos dados amostrais, pois os demais modelos, mesmo com suas irrelevantes diferenças, podem fornecer informações substancialmente distintas sobre predição e sobre o efeito de uma determinada variável explicativa.

\subsection{A ponderação de modelos}

A idéia de se concluir e tomar decisões com base numa combinação de opiniões ou modelos foi inicialmente proposta na década de 1960. Essa idéia foi sistematizada por Leamer (1978) e só a partir da década de 1990 a ponderação de modelos passou a ser mais estudada e aplicada em diversas situações. Assim como muitas outras metodologias estatísticas, a ponderação de modelos pode ser feita sob os enfoques freqüentista e Bayesiano. Em ambos os contextos há o consenso de que a incerteza diante da escolha de um modelo deve ser totalmente incorporada no processo de análise dos dados sempre que a estimação dos parâmetros for sensível a escolha do modelo (Leamer, 1978, p. 91-92 e Buckland et al., 1997). Na concepção de Leamer (1978), a sensibilidade na estimação dos parâmetros pode ser detectada quando diferentes modelos fornecem diferentes estimativas para um mesmo coeficiente 
de regressão.

No contexto freqüentista, Buckland et al. (1997) apresentam uma forma de ponderar modelos. Os pesos de cada modelo podem ser obtidos de três maneiras: pelo critério de informação AIC (Akaike, 1973); pelo critério de informação BIC (Schwarz, 1978) e pelo método bootstrap. Porém, os autores alertam para o fato de que em regressão linear, a utilização do bootstrap pode causar problemas se as amostras bootstrap forem obtidas a partir dos resíduos resultantes do ajuste de um modelo fixado. Os autores defendem sua metodologia argumentando que os resultados obtidos através da aplicação da ponderação Bayesiana podem ser sensíveis a escolha da distribuição a priori para os parâmetros dos modelos. Entretanto, Hoeting (1994) defende a ponderação Bayesiana através de um estudo de sensibilidade, no qual adota três conjuntos de valores para os parâmetros da distribuição a priori conjugada normal-gama atribuída aos parâmetros do modelo, e mostra que os resultados empíricos, condicionados a cada priori, não se diferenciam de forma significativa. Conclusões semelhantes foram obtidas por Raftery et al. (1997) utilizando os mesmos conjuntos de valores.

Candolo (2001) estuda a ponderação de modelos proposta por Buckland em situações de regressão linear simples e múltipla e a compara com o procedimento padrão de seleção de um modelo e com a metodologia de ponderação Bayesiana em termos das propriedades dos estimadores obtidos por cada uma dessas metodologias. Seus resultados mostram que o erro médio quadrático da predição da média da variável resposta $Y$ pode ser substancialmente reduzido pelo uso do estimador ponderado de Buckland nas situações em que os testes para os coeficientes de regressão são pouco significativos. Já nas situações em que os testes para os coeficientes de regressão são altamente significativos, a aplicação da metodologia de Buckland não é justificada, apresentando resultados equivalentes aos obtidos com o uso do modelo selecionado. Os resultados de Candolo (2001) revelam ainda que o cálculo da variância do estimador para a predição sob as diferentes metodologias comparadas forneceram resultados semelhantes, embora seja necessário maior desenvolvimento teórico e empírico para a generalização deste resultado.

Outro trabalho que compara o desempenho das metodologias de ponderação freqüentista e Bayesiana de modelos é o de Candolo (2004), que através de dados simulados, apresenta resultados empíricos que indicam desempenho semelhante à variância dos estimadores obtidos por cada uma das metodologias. 


\subsubsection{A ponderação Bayesiana de modelos}

A ponderação Bayesiana de modelos ou Bayesian Model Averaging (BMA) possibilita ao pesquisador obter uma distribuição a posteriori da quantidade de interesse $\Delta$, que pode ser o efeito de uma variável explicativa, representado por $\beta$ ou a predição da variável resposta $Y$ condicionada a determinados valores das variáveis explicativas, representada por $Y_{0}=Y \mid \mathbf{x}_{\mathbf{0}}$. A estrutura geral do BMA é dada por:

$$
\pi(\Delta \mid \mathbf{y})=\sum_{M_{k} \in \mathcal{C}} \pi\left(\Delta \mid M_{k}, \mathbf{y}\right) p_{M_{k}}
$$

A expressão (4) é uma mistura ponderada das distribuições a posteriori de $\Delta$, $\pi\left(\Delta \mid M_{k}, \mathbf{y}\right)$, sob cada modelo pertencente ao conjunto $\mathcal{C}$. A definição do conjunto $\mathcal{C}$ depende da quantidade populacional a ser representada por $\Delta$. Assim, se $\Delta$ for $Y \mid \mathbf{x}_{\mathbf{0}}, \mathcal{C}$ será formado por todos os $2^{p}$ modelos sem interação que podem ser propostos para representar os dados amostrais quando $p$ variáveis explicativas são observadas, pois neste caso, todos os modelos dão informação acerca de $\Delta$. Se, por outro lado, a quantidade de interesse for $\beta_{j}$, $\mathcal{C}$ será formado apenas pelos modelos que contém $X_{j}$ em seu componente determinístico.

No processo de ponderação, o peso do k-ésimo modelo com vetor de parâmetros $\boldsymbol{\theta}_{\boldsymbol{k}}$ é dado por:

$$
p_{M_{k}}=\frac{P\left(M_{k} \mid \mathbf{y}\right)}{\sum_{M_{l} \in \mathcal{C}} P\left(M_{l} \mid \mathbf{y}\right)}, l=1, \ldots, n(\mathcal{C}),
$$

sendo $n(\mathcal{C})$ o número de modelos contidos em $\mathcal{C}$, e $P\left(M_{k} \mid \mathbf{y}\right)$ a probabilidade condicionada aos dados $\mathbf{y}$ do modelo $M_{k}$ dada por:

$$
P\left(M_{k} \mid \mathbf{y}\right)=\frac{L_{k}(\mathbf{y}) P\left(M_{k}\right)}{\sum_{M_{l} \in \mathcal{C}} L_{l}(\mathbf{y}) P\left(M_{l}\right)},
$$

sendo $P\left(M_{k}\right)$ a probabilidade a priori de $M_{k}, L_{k}(\mathbf{y})$ a função de verossimilhança marginal correspondente ao modelo $M_{k}$, dada por:

$$
L_{k}(\mathbf{y})=\int \ldots \int L\left(\boldsymbol{\theta}_{\boldsymbol{k}} ; \mathbf{y}\right) \pi\left(\boldsymbol{\theta}_{\boldsymbol{k}}\right) d \boldsymbol{\theta}_{\boldsymbol{k}}
$$

sendo $L\left(\boldsymbol{\theta}_{\boldsymbol{k}} ; \mathbf{y}\right)$ a função de verossimilhança de $\boldsymbol{\theta}_{\boldsymbol{k}}$ e $\pi\left(\boldsymbol{\theta}_{\boldsymbol{k}}\right)$ a distribuição a priori de $\boldsymbol{\theta}_{\boldsymbol{k}}$ sob o modelo $M_{k}$.

Geralmente, o pesquisador não tem preferência por um ou outro modelo. Portanto, é comum definir a distribuição uniforme sobre o conjunto $\mathcal{C}$, ou seja: 


$$
P\left(M_{k}\right)=\frac{1}{n(\mathcal{C})} .
$$

Utilizando a medida de divergência da informação de Kullback-Leibler, Madigan \& Raftery (1994) mostram que:

$$
E\left[-\log \left(\sum_{M_{k} \in \mathcal{C}} \pi\left(\Delta \mid M_{k}, \mathbf{y}\right) p_{M_{k}}\right)\right] \leq E\left[-\log \pi\left(\Delta \mid M_{k}, \mathbf{y}\right)\right]
$$

em que as esperanças são referentes a distribuição a posteriori conjunta de $\Delta$ e $M_{k}$. Ou seja, a ponderação Bayesiana de todos os modelos do conjunto $\mathcal{C}$ apresenta, teoricamente, melhor desempenho preditivo em relação ao desempenho de qualquer um dos modelos de $\mathcal{C}$ quando avaliada através do logaritmo do escore preditivo (LEP) proposto por Good (1952).

O principal obstáculo para a aplicação do $B M A$ é a quantidade de modelos contidos em $\mathcal{C}$, que pode ser muito grande dependendo do número de variáveis explicativas observadas. Dentre as principais propostas para contornar este problema estão o Occam's Window (Madigan \& Raftery, 1994), a Composição MCMC (Madigan \& York, 1995) e o stochastic search variable selection (George \& McCulloch, 1993).

O Occam's Window (Madigan \& Raftery, 1994) é um método criado com o propósito de reduzir a quantidade de modelos em $\mathcal{C}$. Segundo os autores, a concepção de pesquisa científica como um processo iterativo onde as hipóteses (ou modelos) menos plausíveis são descartadas(os) em cada iteração até se chegar no conjunto das hipóteses (ou modelos) mais aceitáveis não é representada quanto (4) é diretamente aplicada, pois até mesmo os modelos menos verossímeis de $\mathcal{C}$ diante da amostra obtida são levados em conta.

Portanto, a primeira etapa do Occam's Window tem o objetivo de descartar os modelos menos plausíveis conforme a seguinte regra:

$\left.1^{\circ}\right)$ Eliminar de $\mathcal{C}$ os modelos pertencentes ao conjunto $A$, definido por:

$$
A=\left\{M_{k} \in \mathcal{C}: \frac{\max _{l} P\left[M_{l} \mid \mathbf{y}\right]}{P\left[M_{k} \mid \mathbf{y}\right]}>a\right\}
$$

sendo a definido conforme o contexto da pesquisa. Em seu trabalho, Madigan \& Raftery (1994) utilizam $a=20$ sem uma argumentação mais detalhada. Jeffreys $^{2}$ (1961), citado por Madigan \& Raftery (1994), recomenda o valor de a entre 10 e 100 independentemente do contexto.

\footnotetext{
${ }^{2}$ JEFFREYS, H. Theory of probability. 3. ed. Oxford: Oxford University Press, 1961.
} 
Além disso, o Princípio da Parcimônia ${ }^{3}$ ou Occam's Razor criado por William de Ockham por volta de 1315, preconiza que dentre todas as hipóteses aceitáveis que explicam um acontecimento seja escolhida a mais simples. Esta recomendação é a base para a segunda regra do Occam's Window:

$2^{\circ}$ ) Descartar de $A^{c}=\mathcal{C}-A$, ou seja, descartar do conjunto dos modelos que restaram após a primeira eliminação, os modelos pertencentes ao conjunto $B$, definido por:

$$
B=\left\{M_{k} \in A^{c}: \exists M_{l} \in A^{c}, M_{l} \subset M_{k}, \frac{P\left[M_{l} \mid \mathbf{y}\right]}{P\left[M_{k} \mid \mathbf{y}\right]}>O_{R}\right\},
$$

sendo $O_{R}$ definido pelo usuário. Geralmente, define-se $O_{R}=1$ (Madigan \& Raftery, 1994).

Em suma, a primeira regra promove o descarte dos modelos menos plausíveis enquanto que a segunda regra promove o descarte dos modelos que mostram-se menos aceitáveis em relação aos seus sub-modelos encaixados. Quando apenas a primeira regra é aplicada, dizse que o Occam's Window é simétrico e quando as duas regras são aplicadas, diz-se que o Occam's Window é exato.

Em Madigan \& Raftery (1994) podem ser encontrados algoritmos para a implementação computacional do Occam's Window (OW). Através de resultados empíricos, os autores mostram que a ponderação Bayesiana feita apenas com os modelos selecionados pelo OW apresenta desempenho preditivo muito próximo do desempenho da ponderaçao Bayesiana feita com todos os modelos.

\subsubsection{Desempenho preditivo da ponderação Bayesiana de modelos}

Acredita-se que a multicolinearidade presente em um conjunto de dados possa informar o pesquisador acerca da incerteza diante da escolha de um modelo e, por isso, diferentes situações de incerteza podem ser simuladas através de diferentes graus de multicolinearidade.

O grau de multicolinearidade de um conjunto de dados pode ser medido pelo número de condição $\left(k^{*}\right)$, dado por:

$$
k^{*}=\frac{\lambda_{\max }}{\lambda_{\min }}
$$

sendo $\lambda_{\max }$ e $\lambda_{\min }$, respectivamente, o maior e o menor autovalor da matriz $\mathbf{X}^{\prime} \mathbf{X}$, sendo $\mathbf{X}$ a matriz de valores observados das variáveis explicativas na forma padronizada, sendo que a

\footnotetext{
${ }^{3}$ http://astro.if.ufrgs.br/metodo.htm
} 
j-ésima variável padronizada, $x_{p j}$, é dada por:

$$
x_{p i j}=\frac{x_{i j}-\bar{x}_{j}}{\sqrt{\sum_{i=1}^{n} x_{i j}^{2}-\frac{\left(\sum_{i=1}^{n} x_{i j}\right)^{2}}{n}}}, i=, 1, \ldots, n,(\text { Montgomery \& Peck, 1992). }
$$

Segundo os autores, valores de $k^{*}$ menores que 100 indicam que não há um problema sério de multicolinearidade, já valores de $k^{*}$ entre 100 e 1000 indicam moderada a forte multicolinearidade, e valores acima de 1000 indicam severa multicolinearidade.

Um dos objetivos de Hoeting (1994) é investigar o desempenho preditivo do BMA através de diferentes valores de $k^{*}$. Para isso, a autora utiliza dois conjuntos de dados reais. Seus resultados empíricos mostraram que o desempenho preditivo do BMA foi superior ao desempenho dos métodos de seleção de modelos em condições de extrema multicolinearidade $\left(k^{*} \geq 1000000\right)$.

Outro trabalho que avalia o desempenho preditivo do BMA explorando a questão da quantidade de incerteza envolvida no processo de seleção medida pela correlação existente entre as variáveis é o trabalho de Raftery et al. (1997). Neste trabalho, foi realizado um estudo de simulação e o desempenho preditivo foi medido através da cobertura preditiva, medida pela proporção das observações de um conjunto teste que se encontram dentro dos limites de um intervalo de predição com nível de significância estabelecido pelos autores de 0,10. Seus resultados empíricos mostraram que a cobertura preditiva da ponderação Bayesiana feita utilizando OW foi superior a capacidade preditiva dos métodos usuais de seleção de modelos.

Apesar dos estudos de comparação e avaliação da metodologia BMA estarem atualmente mais em destaque devido, ao ainda, pouco tempo de exploração desta metodologia, podem ser encontrados, na literatura, trabalhos com enfoque mais aplicado, como por exemplo, os trabalhos de Lee III (1999) voltado para a aplicação do BMA em redes neurais e Viallefont et al. (2001) que aplica a ponderação Bayesiana de modelos na epidemiologia. 


\section{MATERIAL E MÉTODOS}

\subsection{Material}

Conforme dados da FAO - Food Agriculture and Organization of the United States, estima-se que $10 \%$ da produção mundial de grãos é perdida durante o período de armazenamento devido ao ataque de pragas, tais como a Sitophilus oryzae (Linné, 1763) (Gallo et. al, 1988). No Brasil, a perda ocorrida durante as fases de colheita e armazenamento de milho, arroz, trigo e feijão na safra de 1991/1992 foi estimada em 20\% de acordo com o IEA - Instituto de Economia Aplicada de São Paulo (Fontes et al., 2003).

Segundo o mesmo IEA ${ }^{4}$, a estimativa da produção total de milho em 2004 no Estado de São Paulo foi de 74.070.779 sc.60Kg (sacas de 60kg). Supondo que o índice de perda de grãos tenha se mantido em $20 \%$ e que essa perda distribui-se uniformemente sobre as culturas citadas, pode-se concluir que a perda estimada do milho, somente no ano de 2004, foi de aproximadamente 3.703 .539 sc.60kg. Considerando-se que, no ano de 2004, os produtores tenham recebido por saca do milho o valor de $\mathrm{R} \$ 16,50$, pode-se concluir que a perda devido ao armazenamento e ao ataque de pragas foi de $\mathrm{R} \$ 61.108 .394,00$.

Portanto, o aperfeiçoamento dos processos de colheita do milho e o melhor controle de pragas podem acarretar em aumento da receita dos produtores. Por essa razão, estudos com o propósito de entender o comportamento das pragas e os danos causados por elas nas diferentes culturas são freqüentemente realizados.

Embora o presente trabalho não esteja voltado para uma discussão sobre o impacto destas questões na economia, é importante que o leitor compreenda os motivos pelos quais os dados apresentados a seguir foram utilizados neste trabalho.

\footnotetext{
${ }^{4}$ Informações obtidas em www.iea.sp.gov.br em 29/07/2005.
} 


\subsubsection{Para a aplicação da metodologia BMA}

Para a aplicação do $B M A$ foram utilizados os dados ${ }^{5}$ amostrais contidos em Matsuo (1986), provenientes de um experimento agronômico conduzido dentro de uma câmara de condições controladas da Universidade Federal do Paraná. Seu objetivo foi verificar os efeitos da intensidade da população de Sitophilus oryzae (Linné, 1763) (Coleoptera - Curculionidae) e do período de armazenamento sobre a perda de peso (em \%) do milho de três diferentes variedades: C-111, Flint-Composto e Piranão.

Os dados de Matsuo, além de contribuirem para o entendimento de uma questão de impacto no cenário econômico, onde novidades metodológicas em análise de dados trazem benefícios importantes para a economia, possuem uma característica técnica importante e diretamente relacionada com os propósitos deste trabalho - que é o fato dos três conjuntos de dados possuirem graus de multicolinearidade bem diferentes um do outro, possibilitando com isso a ampliação das conclusões acerca do BMA.

A respeito de como o experimento foi realizado, Matsuo (1986) explica que cada parcela experimental foi constituída por um frasco contendo 500 (quinhentos) grãos de milho. O delineamento experimental utilizado foi o inteiramente casualizado em esquema fatorial com os seguintes fatores: número de casais de Sitophilus oryzae em 4 níveis (0, 5, 10 e 20 casais), e tempo de armazenamento em 3 níveis (60, 105 e 150 dias), caracterizando um fatorial 4x3. O experimento foi repetido 3 vezes, totalizando 36 observações (3 observações para cada um dos 12 tratamentos). Este mesmo esquema foi seguido em cada um dos cultivares estudados. Além das duas variáveis controladas, denotadas aqui por $X_{1}$ e $X_{2}$, foram observadas outras seis, que são apresentadas a seguir:

$Y$ : Perda de peso (\%)

$X_{1}$ : Número de casais de Sitophilus oryzae.

$X_{2}$ : Produto entre o tempo de armazenamento e 0 (zero) se a parcela não foi infestada, e 1 (um) se a parcela foi infestada.

$X_{3}$ : Teor de carbohidratos $(\%)$

$X_{4}$ : Teor de umidade $(\%)$

\footnotetext{
${ }^{5}$ As variáveis $Y$ e $X_{1}$ já se encontram transformadas em Matsuo para que as suposições do modelo de regressão fossem satisfeitas. No entanto, Matsuo não diz qual função foi utilizada para realizar a transformação.
} 
$X_{5}$ : Teor de matéria seca $(\%)$

$X_{6}$ : Teor de proteínas (\%)

$X_{7}$ : Teor de ácidos graxos (\%)

$X_{8}$ : Índice de acidez dos ácidos graxos (\%)

Os dados referentes aos três cultivares estudados encontram-se nas Tabelas 1,

2 e 3.

Tabela 1. Dados referentes ao cultivar C-111, Paraná, 1976

\begin{tabular}{|c|c|c|c|c|c|c|c|c|c|}
\hline$i$ & $Y$ & $X_{1}$ & $X_{2}$ & $X_{3}$ & $X_{4}$ & $X_{5}$ & $X_{6}$ & $X_{7}$ & $X_{8}$ \\
\hline 1 & 4,360 & 0,707 & 0 & 72,086 & 12,391 & 0,987 & 10,005 & 4,530 & 24,336 \\
\hline 2 & 5,437 & 0,707 & 0 & 72,865 & 12,607 & 0,951 & 8,936 & 4,641 & 26,212 \\
\hline 3 & 5,425 & 0,707 & 0 & 72,568 & 12,529 & 0,951 & 9,629 & 4,322 & 22,630 \\
\hline 4 & 9,418 & 6,819 & 60 & 70,977 & 12,949 & 1,031 & 10,469 & 4,572 & 22,113 \\
\hline 5 & 8,148 & 6,519 & 60 & 72,167 & 12,581 & 0,999 & 9,777 & 4,474 & 28,147 \\
\hline 6 & 7,649 & 4,743 & 60 & 72,195 & 12,615 & 1,105 & 9,495 & 4,588 & 27,263 \\
\hline 7 & 15,370 & 12,786 & 60 & 71,073 & 13,142 & 1,041 & 9,909 & 4,735 & 44,133 \\
\hline 8 & 12,485 & 9,823 & 60 & 72,216 & 12,979 & 1,001 & 9,035 & 4,767 & 36,757 \\
\hline 9 & 14,940 & 13,473 & 60 & 72,634 & 13,039 & 1,107 & 8,576 & 4,644 & 40,565 \\
\hline 10 & 17,276 & 13,209 & 60 & 71,390 & 13,005 & 1,040 & 9,673 & 4,891 & 42,461 \\
\hline 11 & 14,586 & 11,379 & 60 & 71,801 & 13,280 & 1,030 & 9,027 & 4,861 & 40,492 \\
\hline 12 & 16,118 & 12,980 & 60 & 71,956 & 13,048 & 1,035 & 9,341 & 4,620 & 41,236 \\
\hline 13 & 6,812 & 0,707 & 0 & 72,680 & 12,951 & 1,155 & 8,792 & 4,420 & 31,440 \\
\hline 14 & 6,632 & 0,707 & 0 & 72,867 & 12,835 & 1,224 & 8,520 & 4,552 & 33,835 \\
\hline 15 & 7,927 & 0,707 & 0 & 72,400 & 13,024 & 1,235 & 8,897 & 4,444 & 29,245 \\
\hline 16 & 13,644 & 8,031 & 105 & 70,700 & 13,371 & 1,287 & 9,897 & 4,744 & 42,660 \\
\hline 17 & 17,484 & 11,022 & 105 & 71,325 & 13,498 & 1,281 & 9,323 & 4,571 & 43,550 \\
\hline 18 & 9,842 & 6,123 & 105 & 71,334 & 13,206 & 1,209 & 9,660 & 4,590 & 36,945 \\
\hline 19 & 22,991 & 14,983 & 105 & 69,840 & 13,556 & 1,393 & 10,273 & 4,938 & 67,534 \\
\hline 20 & 25,814 & 17,762 & 105 & 69,274 & 13,659 & 1,340 & 10,856 & 4,870 & 97,399 \\
\hline 21 & 25,718 & 18,207 & 105 & 69,728 & 13,457 & 1,411 & 10,221 & 5,182 & 93,434 \\
\hline 22 & 22,640 & 14,747 & 105 & 70,049 & 13,118 & 1,326 & 10,346 & 5,161 & 56,625 \\
\hline 23 & 31,502 & 22,726 & 105 & 70,028 & 13,412 & 1,412 & 10,473 & 4,674 & 148,556 \\
\hline 24 & 30,361 & 21,737 & 105 & 68,504 & 13,951 & 1,445 & 11,883 & 4,215 & 172,521 \\
\hline 25 & 4,009 & 0,707 & 0 & 72,932 & 12,470 & 1,210 & 9,147 & 4,240 & 15,842 \\
\hline 26 & 4,887 & 0,707 & 0 & 72,225 & 12,777 & 1,146 & 9,456 & 4,395 & 15,647 \\
\hline 27 & 5,239 & 0,707 & 0 & 72,872 & 12,842 & 1,207 & 8,680 & 4,397 & 15,934 \\
\hline 28 & 23,085 & 13,693 & 150 & 70,312 & 12,898 & 1,226 & 9,734 & 4,628 & 37,867 \\
\hline 29 & 24,806 & 15,475 & 150 & 69,680 & 13,428 & 1,356 & 10,740 & 4,795 & 36,988 \\
\hline 30 & 22,747 & 14,300 & 150 & 71,289 & 13,503 & 1,228 & 9,199 & 4,780 & 34,643 \\
\hline 31 & 22,317 & 13,583 & 150 & 69,964 & 13,953 & 2,418 & 9,892 & 3,773 & 41,520 \\
\hline 32 & 24,088 & 14,439 & 150 & 69,531 & 13,587 & 2,495 & 9,588 & 4,798 & 35,405 \\
\hline 33 & 30,147 & 17,930 & 150 & 70,322 & 13,241 & 1,939 & 9,849 & 4,648 & 43,233 \\
\hline 34 & 31,096 & 19,634 & 150 & 69,936 & 13,345 & 2,307 & 10,195 & 4,217 & 71,769 \\
\hline 35 & 24,646 & 16,688 & 150 & 71,369 & 13,000 & 1,961 & 9,023 & 4,646 & 38,676 \\
\hline 36 & 30,432 & 19,912 & 150 & 70,026 & 12,934 & 2,472 & 10,377 & 4,189 & 66,272 \\
\hline
\end{tabular}


Tabela 2. Dados referentes ao cultivar Piranão, Paraná, 1976

\begin{tabular}{|c|c|c|c|c|c|c|c|c|c|}
\hline$i$ & $Y$ & $X_{1}$ & $X_{2}$ & $X_{3}$ & $X_{4}$ & $X_{5}$ & $X_{6}$ & $X_{7}$ & $X_{8}$ \\
\hline 1 & 4,761 & 0,707 & 0 & 69,498 & 12,096 & 1,036 & 12,849 & 4,520 & 20,684 \\
\hline 2 & 4,131 & 0,707 & 0 & 69,014 & 12,124 & 1,000 & 13,068 & 4,791 & 18,622 \\
\hline 3 & 4,360 & 0,707 & 0 & 68,621 & 12,112 & 0,850 & 13,584 & 4,830 & 13,974 \\
\hline 4 & 10,167 & 7,176 & 60 & 67,591 & 12,509 & 1,028 & 14,067 & 4,801 & 13,759 \\
\hline 5 & 12,762 & 11,423 & 60 & 66,703 & 13,057 & 1,076 & 14,049 & 5,112 & 17,155 \\
\hline 6 & 10,120 & 8,573 & 60 & 67,670 & 12,649 & 1,157 & 13,895 & 4,628 & 15,751 \\
\hline 7 & 11,394 & 10,793 & 60 & 67,106 & 12,831 & 1,271 & 13,910 & 4,879 & 17,238 \\
\hline 8 & 11,762 & 10,024 & 60 & 67,667 & 12,835 & 1,201 & 13,553 & 4,743 & 16,273 \\
\hline 9 & 8,730 & 7,314 & 60 & 67,891 & 12,126 & 1,194 & 14,133 & 4,653 & 15,453 \\
\hline 10 & 11,155 & 9,974 & 60 & 69,535 & 12,981 & 1,182 & 12,807 & 4,493 & 13,039 \\
\hline 11 & 11,269 & 10,464 & 60 & 67,635 & 12,489 & 1,254 & 14,087 & 4,533 & 15,607 \\
\hline 12 & 11,955 & 9,624 & 60 & 66,860 & 12,969 & 1,301 & 14,195 & 4,672 & 20,872 \\
\hline 13 & 6,971 & 0,707 & 0 & 68,479 & 12,716 & 1,306 & 13,175 & 4,321 & 10,775 \\
\hline 14 & 6,802 & 0,707 & 0 & 68,663 & 12,721 & 1,408 & 13,008 & 4,296 & 9,189 \\
\hline 15 & 7,158 & 0,707 & 0 & 68,937 & 12,648 & 1,362 & 12,939 & 4,112 & 8,624 \\
\hline 16 & 14,485 & 9,513 & 105 & 68,593 & 13,031 & 1,311 & 12,531 & 4,541 & 20,206 \\
\hline 17 & 15,435 & 13,583 & 105 & 68,719 & 13,003 & 1,379 & 12,420 & 4,477 & 20,411 \\
\hline 18 & 17,299 & 11,379 & 105 & 68,932 & 12,725 & 1,337 & 12,489 & 4,514 & 20,352 \\
\hline 19 & 20,418 & 16,598 & 105 & 67,298 & 13,071 & 1,344 & 13,597 & 4,687 & 31,702 \\
\hline 20 & 17,248 & 14,781 & 105 & 67,670 & 12,875 & 1,351 & 13,553 & 4,548 & 21,293 \\
\hline 21 & 12,644 & 10,977 & 105 & 68,197 & 12,951 & 1,369 & 13,237 & 4,244 & 15,885 \\
\hline 22 & 19,985 & 16,263 & 105 & 66,351 & 13,090 & 1,427 & 14,610 & 4,552 & 33,712 \\
\hline 23 & 17,427 & 12,780 & 105 & 67,155 & 13,820 & 1,386 & 13,674 & 3,962 & 47,854 \\
\hline 24 & 21,564 & 17,902 & 105 & 67,300 & 12,915 & 1,309 & 14,082 & 4,396 & 21,446 \\
\hline 25 & 5,802 & 0,707 & 0 & 68,850 & 12,780 & 1,558 & 12,680 & 4,129 & 10,712 \\
\hline 26 & 6,083 & 0,707 & 0 & 66,584 & 12,713 & 1,949 & 14,394 & 4,359 & 10,222 \\
\hline 27 & 5,724 & 0,707 & 0 & 68,251 & 12,478 & 1,812 & 12,952 & 4,505 & 9,307 \\
\hline 28 & 18,006 & 11,247 & 150 & 67,515 & 13,258 & 1,450 & 13,282 & 4,491 & 20,511 \\
\hline 29 & 23,489 & 14,815 & 150 & 63,129 & 14,215 & 1,716 & 16,712 & 4,227 & 49,043 \\
\hline 30 & 17,133 & 11,510 & 150 & 64,194 & 13,373 & 1,582 & 16,271 & 4,578 & 32,980 \\
\hline 31 & 21,939 & 13,209 & 150 & 66,350 & 13,594 & 1,467 & 14,478 & 4,109 & 34,350 \\
\hline 32 & 23,001 & 16,263 & 150 & 65,977 & 13,807 & 2,092 & 13,439 & 4,682 & 21,882 \\
\hline 33 & 17,022 & 10,885 & 150 & 65,310 & 13,398 & 3,064 & 13,863 & 4,363 & 26,330 \\
\hline 34 & 32,163 & 24,259 & 150 & 63,145 & 14,825 & 3,453 & 15,762 & 2,812 & 125,530 \\
\hline 35 & 29,271 & 17,449 & 150 & 61,989 & 14,708 & 2,039 & 17,031 & 4,230 & 66,520 \\
\hline 36 & 26,660 & 21,644 & 150 & 65,631 & 14,611 & 3,000 & 14,329 & 2,427 & 86,761 \\
\hline
\end{tabular}


Tabela 3. Dados referentes ao cultivar Flint Composto, Paraná, 1976

\begin{tabular}{|c|c|c|c|c|c|c|c|c|c|}
\hline$i$ & $Y$ & $X_{1}$ & $X_{2}$ & $X_{3}$ & $X_{4}$ & $X_{5}$ & $X_{6}$ & $X_{7}$ & $X_{8}$ \\
\hline 1 & 4,314 & 0,707 & 0 & 68,457 & 11,953 & 0,958 & 13,810 & 4,819 & 52,665 \\
\hline 2 & 5,367 & 0,707 & 0 & 68,382 & 12,183 & 1,007 & 13,689 & 4,736 & 46,486 \\
\hline 3 & 4,592 & 0,707 & 0 & 68,400 & 12,120 & 0,910 & 13,740 & 4,819 & 43,469 \\
\hline 4 & 6,398 & 4,301 & 60 & 67,695 & 12,294 & 1,263 & 14,010 & 4,735 & 49,628 \\
\hline 5 & 10,861 & 7,516 & 60 & 67,152 & 12,645 & 1,309 & 14,119 & 4,773 & 45,535 \\
\hline 6 & 9,390 & 7,382 & 60 & 66,999 & 12,810 & 1,283 & 14,138 & 4,767 & 49,102 \\
\hline 7 & 11,683 & 11,811 & 60 & 66,246 & 12,924 & 1,353 & 14,393 & 5,082 & 73,487 \\
\hline 8 & 10,216 & 8,689 & 60 & 67,148 & 12,495 & 1,333 & 14,012 & 5,010 & 67,999 \\
\hline 9 & 10,504 & 9,772 & 60 & 67,616 & 12,974 & 1,218 & 13,660 & 4,529 & 72,560 \\
\hline 10 & 14,998 & 13,509 & 60 & 66,833 & 13,258 & 1,026 & 13,645 & 5,235 & 76,588 \\
\hline 11 & 12,828 & 11,853 & 60 & 67,052 & 12,703 & 1,104 & 14,082 & 5,057 & 51,152 \\
\hline 12 & 13,156 & 10,653 & 60 & 67,379 & 12,692 & 1,327 & 13,651 & 4,949 & 59,561 \\
\hline 13 & 8,177 & 0,707 & 0 & 67,103 & 13,029 & 1,808 & 13,435 & 4,622 & 31,989 \\
\hline 14 & 7,321 & 0,707 & 0 & 67,544 & 12,759 & 1,592 & 13,470 & 4,633 & 32,437 \\
\hline 15 & 7,636 & 0,707 & 0 & 67,285 & 12,690 & 1,602 & 13,633 & 4,787 & 31,176 \\
\hline 16 & 16,674 & 12,469 & 105 & 66,420 & 13,138 & 1,768 & 13,734 & 4,936 & 49,933 \\
\hline 17 & 15,150 & 9,354 & 105 & 65,472 & 13,516 & 1,637 & 14,442 & 4,931 & 39,769 \\
\hline 18 & 10,488 & 5,244 & 105 & 66,463 & 13,245 & 1,326 & 14,059 & 4,905 & 47,242 \\
\hline 19 & 16,882 & 13,729 & 105 & 66,817 & 13,061 & 1,668 & 13,675 & 4,777 & 78,162 \\
\hline 20 & 11,922 & 8,514 & 105 & 65,875 & 13,042 & 1,914 & 14,350 & 4,817 & 81,616 \\
\hline 21 & 16,342 & 11,510 & 105 & 66,094 & 13,540 & 2,254 & 13,418 & 4,732 & 86,797 \\
\hline 22 & 17,532 & 13,838 & 105 & 65,098 & 13,521 & 2,048 & 14,530 & 4,801 & 57,121 \\
\hline 23 & 15,808 & 12,629 & 105 & 66,961 & 13,142 & 1,349 & 13,767 & 4,779 & 53,729 \\
\hline 24 & 16,647 & 14,017 & 105 & 66,134 & 13,219 & 1,569 & 14,451 & 4,624 & 55,329 \\
\hline 25 & 6,447 & 0,707 & 0 & 68,095 & 12,979 & 1,497 & 13,071 & 4,356 & 26,710 \\
\hline 26 & 7,156 & 0,707 & 0 & 66,437 & 13,066 & 1,460 & 14,253 & 4,782 & 22,299 \\
\hline 27 & 7,606 & 0,707 & 0 & 67,919 & 13,203 & 1,462 & 12,968 & 4,445 & 21,305 \\
\hline 28 & 22,904 & 14,815 & 150 & 63,292 & 14,523 & 2,387 & 14,951 & 4,844 & 42,634 \\
\hline 29 & 16,041 & 9,513 & 150 & 64,680 & 13,978 & 1,592 & 14,762 & 4,729 & 31,535 \\
\hline 30 & 21,393 & 14,089 & 150 & 64,384 & 14,040 & 1,734 & 14,894 & 4,946 & 35,211 \\
\hline 31 & 23,779 & 13,656 & 150 & 65,650 & 14,069 & 1,435 & 14,085 & 4,759 & 47,302 \\
\hline 32 & 19,382 & 13,133 & 150 & 66,222 & 13,689 & 1,186 & 14,039 & 4,861 & 40,428 \\
\hline 33 & 26,115 & 16,896 & 150 & 64,783 & 14,049 & 1,421 & 15,028 & 4,716 & 49,292 \\
\hline 34 & 24,675 & 16,263 & 150 & 63,391 & 14,422 & 1,139 & 16,703 & 4,343 & 64,506 \\
\hline 35 & 22,855 & 15,732 & 150 & 64,398 & 13,752 & 1,217 & 15,662 & 4,969 & 43,935 \\
\hline 36 & 32,691 & 21,459 & 150 & 62,353 & 15,646 & 1,434 & 18,235 & 2,330 & 115,699 \\
\hline
\end{tabular}




\subsubsection{Para a avaliação do desempenho preditivo do BMA}

A comparação entre o desempenho preditivo da ponderação Bayesiana e o desempenho preditivo dos critérios $^{6}$ de seleção de modelos foi feita através de dados simulados obtidos a partir da utilização de medidas descritivas referentes aos dados dos três cultivares. As medidas descritivas utilizadas foram: $\overline{\mathbf{x}}$ (vetor de médias amostral), $\mathbf{S}$ (matriz de variâncias

e covariâncias amostral), $\widehat{\boldsymbol{\beta}}$ (estimativa do vetor dos coeficientes de regressão do modelo com todas as variáveis explicativas observadas) e $Q M R e s$ (a estimativa de $\sigma^{2}$ obtida pelo ajuste do mesmo modelo).

Os graus de multicolinearidade medido pelo número de condição da matriz X'X padronizada encontrados foram: 391,39 (cultivar C-111), 1232,68 (cultivar Piranão) e 12826,39 (Flint Composto), os quais indicam, respectivamente, moderada, forte e severa multicolinearidade.

Segundo Hoeting (1994), grau de multicolinearidade elevado pode contribuir para aumentar a incerteza do pesquisador diante da escolha de um modelo. Em situações deste tipo pode ser interessante a utilização de métodos que permitem combinar informações de diferentes modelos acerca de determinadas quantidades populacionais.

Foram geradas amostras de tamanho amostral 50, 75 e 100. Para cada tamanho amostral considerado foram geradas 1000 amostras utilizando as medidas descritivas de cada um dos cultivares, totalizando 9000 amostras, sendo 1000 para cada combinação entre tamanho amostral e cultivar.

As variáveis explicativas e a variável resposta foram respectivamente geradas da seguinte forma:

$$
\begin{gathered}
\mathbf{X}_{i}^{\prime}=\left(X_{i 1}, X_{i 2}, \ldots, X_{i 8}\right) \sim N(\overline{\mathbf{x}}, \mathbf{S}) ; \quad i=1,2, \ldots, n . \\
Y_{i}=\mathbf{X}_{i}^{\prime} \widehat{\boldsymbol{\beta}}+\varepsilon_{i}, \quad i=1,2, \ldots, n
\end{gathered}
$$

sendo $\varepsilon_{i} \sim N(0, Q M R e s)$. Portanto, todos os conjuntos simulados possuem oito variáveis explicativas $X_{1}, X_{2}, \ldots, X_{8}$ e uma variável resposta $Y$. logo, a cada simulação foi obtido um conjunto de dados com a seguinte estrutura:

\footnotetext{
${ }^{6}$ Os critérios avaliados foram: Maior $R^{2}$; Maior $\bar{R}^{2}$; Menor $C_{p}$ e PRESS. Todos esses critérios encontram-se definidos em 2.1.
} 
Tabela 4. Ilustração de um específico conjunto de dados simulado

\begin{tabular}{cccccccccc}
\hline$i$ & $y_{i}$ & $x_{i 1}$ & $x_{i 2}$ & $x_{i 3}$ & $x_{i 4}$ & $x_{i 5}$ & $x_{i 6}$ & $x_{i 7}$ & $x_{i 8}$ \\
\hline 1 & $y_{1}$ & $x_{11}$ & $x_{12}$ & $x_{13}$ & $x_{14}$ & $x_{15}$ & $x_{16}$ & $x_{17}$ & $x_{18}$ \\
2 & $y_{2}$ & $x_{21}$ & $x_{22}$ & $x_{23}$ & $x_{24}$ & $x_{25}$ & $x_{26}$ & $x_{27}$ & $x_{28}$ \\
$\vdots$ & $\vdots$ & $\vdots$ & $\vdots$ & $\vdots$ & $\vdots$ & $\vdots$ & $\vdots$ & $\vdots$ & $\vdots$ \\
$n$ & $y_{n}$ & $x_{n 1}$ & $x_{n 2}$ & $x_{n 3}$ & $x_{n 4}$ & $x_{n 5}$ & $x_{n 6}$ & $x_{n 7}$ & $x_{n 8}$ \\
\hline
\end{tabular}

\subsection{Métodos}

A ponderação Bayesiana pode ser aplicada em várias classes de modelos com o propósito de combinar informações acerca de uma determinada quantidade de interesse, representada neste trabalho por $\Delta$. Nesse trabalho serão considerados, somente, modelos de regressão linear clássica.

\subsubsection{Ponderação Bayesiana de modelos de regressão linear clássica}

Considere o modelo de regressão linear clássica representado por:

$$
Y_{i}=\beta_{0}+\sum_{j=1}^{p} \beta_{j} X_{i j}+\varepsilon_{i},
$$

$\operatorname{com} \varepsilon_{i} \sim N\left(0, \sigma^{2}\right), i=1, \ldots, n$, sendo que:

$$
\operatorname{cov}\left(\varepsilon_{i}, \varepsilon_{i^{\prime}}\right)= \begin{cases}1 & \text { se } i=i^{\prime} \\ 0 & \text { se } i \neq i^{\prime}\end{cases}
$$

Desde que sejam observadas $p$ variáveis explicativas em um experimento, o número de modelos cuja forma é dada por (9) é igual a $2^{p}$. Representando por $\mathcal{C}$ o conjunto que contém todos esses modelos, tem-se então que $n(\mathcal{C})=2^{p}$.

O $k$-ésimo modelo de $\mathcal{C}$ pode ser rescrito na forma matricial da seguinte forma:

$$
M_{k}: \mathbf{Y} \sim N\left(\mathbf{X}_{k} \boldsymbol{\beta}_{k}, \sigma^{2} \mathbf{I}_{k}\right)
$$

em que

(i) Y é o vetor aleatório $n$ dimensional que representa a variável resposta; 
(ii) $\mathbf{X}_{k}$ é a matriz de dimensão $n \times\left(p_{k}+1\right)$ dos valores observados das $p_{k}$ variáveis explicativas contidas no modelo $M_{k}$;

(iii) $\left(\boldsymbol{\beta}_{k}, \sigma^{2}\right)^{\prime}=\boldsymbol{\theta}_{k}$, sendo $\boldsymbol{\beta}_{k}=\left(\beta_{0}, \beta_{1}, \ldots, \beta_{p_{k}}\right)^{\prime}$ o vetor dos coeficientes de regressão de dimensão $\left(p_{k}+1\right) \times 1$.

A quantidade de interesse do pesquisador,$\Delta$, pode ser o efeito de uma variável explicativa sobre $Y$, suponha que seja $\beta_{j}$, neste caso, para a aplicação do BMA deve-se considerar apenas os modelos pertencentes a $\mathcal{C}$ que contêm o coeficiente de regressão $\beta_{j}$. Logo, a ponderação Bayesiana será feita sobre os modelos pertencentes ao conjunto $\mathcal{C}_{\Delta}$, definido por:

$$
\mathcal{C}_{\Delta}=\left\{M_{k} \in \mathcal{C} \mid \beta_{j} \in \boldsymbol{\beta}_{k}\right\}
$$

Por outro lado, a quantidade de interesse do pesquisador,$\Delta$, pode ser a predição da variável resposta condicionada a determinados valores das variáveis explicativas, $Y \mid \mathbf{x}_{0}$, neste caso, a ponderação deve ser feita levando-se em conta todos os $2^{p}$ modelos, pois todos transmitem informação acerca do valor futuro de $Y, \log$ o, $\mathcal{C}_{\Delta}=\mathcal{C}$.

De acordo com a estrutura geral do BMA dada pelas expresões (4), (5) e (6), deve-se a princípio ser definida:

(i) $\pi\left(\boldsymbol{\theta}_{k}\right)$, a distribuição a priori para $\boldsymbol{\theta}_{k}=\left(\boldsymbol{\beta}_{k}^{\prime}, \sigma^{2}\right)$ e;

(ii) $P\left(M_{k}\right)$, as probabilidades a priori para os modelos de $\mathcal{C}_{\Delta}$.

Com relação a (i), foi adotada neste trabalho a distribuição priori conjugada normal-gama com a seguinte parametrização:

$$
\begin{aligned}
\boldsymbol{\beta}_{k} \mid \sigma^{2} & \sim N\left(\boldsymbol{\mu}_{k}, \sigma^{2} \mathbf{V}_{k}\right) \\
\sigma^{2} & \sim \text { Gamma-invertida }\left(\frac{\nu}{2}, \frac{\nu \lambda}{2}\right),
\end{aligned}
$$

e dessa forma tem-se que

$$
\pi\left(\boldsymbol{\theta}_{k}\right)=(2 \pi)^{-\left(p_{k}+1\right) / 2}\left|\sigma^{2} \mathbf{V}_{k}\right|^{-1 / 2} e^{\left\{-\frac{1}{2}\left(\boldsymbol{\beta}_{k}-\boldsymbol{\mu}_{k}\right)^{\prime}\left(\sigma^{2} \mathbf{V}_{k}\right)^{-1}\left(\boldsymbol{\beta}_{k}-\boldsymbol{\mu}_{k}\right)\right\}} \frac{(\nu \lambda / 2)^{\nu / 2}}{\Gamma(\nu / 2)} \sigma^{2-(\nu / 2-1)} e^{\frac{-\nu \lambda}{2 \sigma^{2}}}
$$

sendo a opinião subjetiva do pesquisador representada pelos valores de $\boldsymbol{\mu}_{k}, \mathbf{V}_{k}, \nu, \lambda$ e $\phi$, definidos por: 


$$
\boldsymbol{\mu}_{k}=\left(\begin{array}{c}
\widehat{\beta}_{0} \\
0 \\
\vdots \\
0
\end{array}\right)
$$

sendo $\widehat{\beta}_{0}$ a estimativa de mínimos quadrados de $\beta_{0}$ sob o modelo $M_{k}$ e

$$
\mathbf{V}_{\mathbf{k}}=\left(\begin{array}{cccccccc}
s_{Y}^{2} & 0 & 0 & 0 & 0 & 0 & 0 & 0 \\
0 & \phi^{2} / s_{X_{1}}^{2} & 0 & & \vdots & & \vdots & \vdots \\
\vdots & 0 & \phi^{2} / s_{X_{1}}^{2} & & \vdots & & \vdots & \vdots \\
\vdots & \vdots & 0 & \ddots & 0 & & \vdots & \vdots \\
\vdots & \vdots & \vdots & & \phi^{2} / s_{X_{j}}^{2} & \vdots & \vdots \\
\vdots & \vdots & \vdots & & 0 & \ddots & 0 & \vdots \\
\vdots & \vdots & \vdots & & \vdots & & \phi^{2} / s_{X_{p_{k}-1}}^{2} & 0 \\
0 & 0 & 0 & 0 & 0 & 0 & 0 & \phi^{2} / s_{X_{p_{k}}}^{2}
\end{array}\right)
$$

com todos os elementos fora da diagonal principal iguais a zero, sendo $s_{Y}^{2}$ a variância amostral de $Y$ e $s_{X_{j}}^{2}$ a variância amostral da $j$-ésima variável explicativa contida em $M_{k}$ e $\nu, \lambda$ e $\phi$ podendo assumir um dos três conjuntos de valores (Tabela 6).

Tabela 5. Opções para os valores dos hiperparâmetros

\begin{tabular}{cccc}
\hline Conjunto & $\nu$ & $\lambda$ & $\phi$ \\
\hline 1 & 0,17 & 0,59 & 5,29 \\
2 & 0,28 & 1,29 & 2,86 \\
3 & 2,58 & 0,28 & 2,85 \\
\hline
\end{tabular}

Essas possibilidades de valores para $\nu, \lambda$ e $\phi$ são os resultados obtidos por Hoeting (1994) após a resolução de um sistema com as seguintes restrições:

(i) A distribuição a priori para $\left(\beta_{0}, \beta_{1}, \ldots, \beta_{p_{k}}\right)$ deve ser razoavelmente "flat"sobre o hipercubo $[-1,1]^{p_{k}}$;

(ii) A distribuição a priori para $\sigma^{2}$ deve ser razoavelmente "flat" sobre o intervalo $(a, 1)$ para um $a$ pequeno; 
(iii) Seja o evento $\left\{\sigma^{2}<1\right\}$. A probabilidade de ocorrência deste evento deve ser maximizada.

Dizemos que há uma conjugação entre as distribuições a priori e posteriori quando a distribuição a posteriori possui a mesma forma paramétrica da distribuição a priori. A adoção de famílias conjugadas é algo freqüente em análise de dados sob enfoque Bayesiano pela conveniência matemática e computacional trazida por ela, além de facilitar a interpretação dos resultados pelo fato dos parâmetros da posteriori serem basicamente os parâmetros da priori atualizados com a informação da amostra, transmitida através da função de verossimilhança. Porém, tais conveniências não devem se sobrepor ao objetivo principal do processo Bayesiano de análise, que é a representação adequada da opinião subjetiva do pesquisador. Sendo assim, famílias conjugadas só devem ser adotadas se o objetivo principal puder ser atendido, caso contrário, deve-se priorizar a representatividade da opinião do pesquisador com uma priori mais adequada, mesmo que a posteriori resultante tenha uma forma desconhecida, ou seja, não tenha a forma de alguma das funções densidade conhecidas da literatura.

Embora a priori aqui adotada não comprometa o interesse principal deste trabalho, que é a avaliação do desempenho preditivo do BMA, é bom ressaltar que, para trabalhos nos quais o objetivo é a análise dos dados e não estudos comparativos, as informações do pesquisador acerca do fenômeno em estudo devem estar devidamente representadas, logo, os hiperparâmetros devem assumir valores que representem as opiniões do pesquisador.

Os hiperparâmetros $\nu$ e $\lambda$ definem a forma da distribuição probabilística de $\sigma^{2}$ (a variância do termo aleatório dos modelos). Já o conhecimento prévio acerca dos coeficientes de regressão linear é expresso através de $\phi$, de modo que valores maiores de $\phi$ representam maior dispersão em torno do valor esperado dos coeficientes. Por exemplo, valores entre 2,50 a 3,50 representam informações mais precisas a respeito do efeito das variáveis explicativas que valores entre 4,00 a 5,00.

A Figura 2 ilustra as diferentes formas da distribuição a priori de $\sigma^{2}$ para cada conjunto de valores da Tabela 6 . Todos os conjuntos representam a opinião subjetiva do pesquisador acerca do erro experimental, que de acordo com o que se pode observar, a opinião subjetiva do pesquisador a respeito do controle do erro experimental realizado é a de que os fatores que mais influenciam a variabilidade da resposta foram controlados.

Com relação a (ii) (as probabilidades a priori para os modelos de $\mathcal{C}_{\Delta}$ ), geral- 


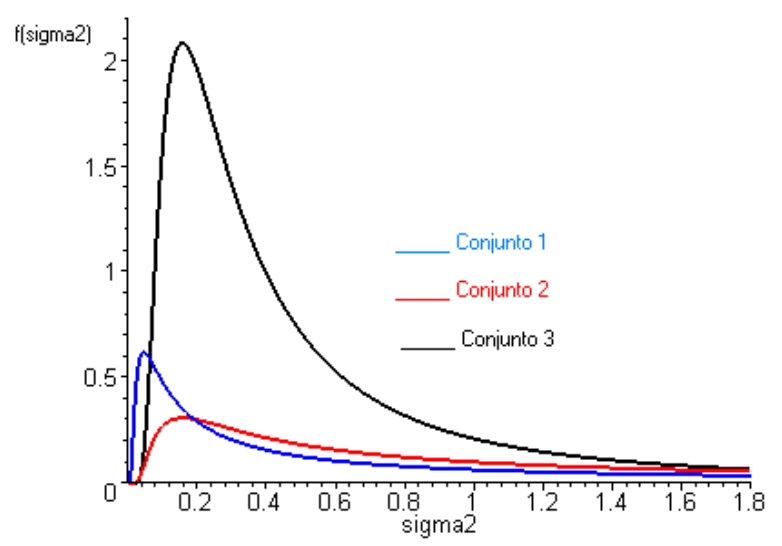

Figura 2 - Distribuições a priori para $\sigma^{2}$ segundo valores de $\nu$ e $\lambda$

mente o pesquisador não tem preferência por um modelo específico de $\mathcal{C}_{\Delta}$ antes da realização do experimento e por essa razão, costuma-se atribuir probabilidades iguais para todos os modelos, deste modo:

$$
P\left(M_{k}\right)=\frac{1}{n\left(\mathcal{C}_{\Delta}\right)}, \forall M_{k} \in \mathcal{C}_{\Delta}
$$

Após as definições de (i) e (ii), que constituem as etapas do BMA nas quais as opiniões subjetivas são tratadas probabilisticamente, e etapa seguinte envolve a obtenção da função de verossimilhança marginal $L_{k}(\mathbf{y})$ conforme (6). Para isso, é necessário combinar a distribuição a priori e a função de verossimilhança de $\boldsymbol{\theta}_{k}$. A função de verossimilhança de $\boldsymbol{\theta}_{k}$, definida por:

$$
L\left(\boldsymbol{\theta}_{\boldsymbol{k}} ; \mathbf{y}_{1}, \ldots, \mathbf{y}_{n}\right)=\prod_{i=1}^{n} f_{\mathbf{Y}_{i}}\left(\mathbf{y}_{i} \mid \boldsymbol{\theta}_{\boldsymbol{k}}\right)=\prod_{i=1}^{n} f_{\mathbf{Y}_{i}}\left(\mathbf{y}_{i} \mid \boldsymbol{\beta}_{\boldsymbol{k}}, \sigma^{2}\right),
$$

sendo $f_{\mathbf{Y}_{i}}\left(\mathbf{y}_{i} \mid \boldsymbol{\beta}_{\boldsymbol{k}}, \sigma^{2}\right)$ a função densidade de probablidade de $\mathbf{Y}_{i}$. Como no modelo de regressão linear clássica as $n$ observações da variável $Y$ podem ser vistas como elementos de um vetor $\mathbf{y}$ de dimensão $n$ que segue distribuição normal com média $\mathbf{X}_{k} \boldsymbol{\beta}_{\boldsymbol{k}}$ e variância $\sigma^{2} \mathbf{I}$, a função de verossimilhança de $\boldsymbol{\theta}_{\boldsymbol{k}}$ é dada por:

$$
L\left(\boldsymbol{\theta}_{k} ; \mathbf{y}\right)=\left|2 \pi \sigma^{2} \mathbf{I}\right|^{-n / 2} e^{\left\{-\frac{1}{2}\left(\mathbf{y}-\mathbf{X}_{k} \boldsymbol{\beta}_{k}\right)^{\prime}\left(\sigma^{2} \mathbf{I}\right)^{-1}\left(\mathbf{y}-\mathbf{X}_{k} \boldsymbol{\beta}_{k}\right)\right\}} .
$$

Assim, a função de verossimilhança marginal $L_{k}(\mathbf{y})$ correspondente ao $k$-ésimo 
modelo de regressão linear clássica é dada por:

$$
\begin{aligned}
L_{k}(\mathbf{y}) & =\int_{-\infty}^{\infty} \int_{0}^{\infty} \cdots \int_{0}^{\infty} L\left(\boldsymbol{\theta}_{k} ; \mathbf{y}\right) \pi\left(\boldsymbol{\beta}_{k} \mid \sigma^{2}\right) \pi\left(\sigma^{2}\right) d \sigma^{2} d \boldsymbol{\beta}_{k} \\
& =\frac{\Gamma\left(\frac{n+\nu}{2}\right)\left|\lambda\left(\mathbf{I}+\mathbf{X}_{k} \mathbf{V}_{k} \mathbf{X}_{k}^{\prime}\right)\right|^{-1 / 2}}{\Gamma(\nu / 2) \nu^{n / 2} \pi^{n / 2}} \\
& \mathbf{x}\left[1+\frac{1}{\nu}\left(\mathbf{y}-\mathbf{X}_{k} \boldsymbol{\mu}_{k}\right)^{\prime}\left(\lambda\left(\mathbf{I}+\mathbf{X}_{\mathbf{k}} \mathbf{V}_{k} \mathbf{X}_{k}^{\prime}\right)\right)^{-1}\left(\mathbf{y}-\mathbf{X}_{k} \boldsymbol{\mu}_{k}\right)\right]^{\frac{-(n+\nu)}{2}}
\end{aligned}
$$

que corresponde a função densidade de probabilidade de uma distribuição $t$ de Student $n$ dimensional com $\nu$ graus de liberdade, média $\mathbf{X}_{k} \boldsymbol{\mu}_{k}$ e variância $\frac{\nu}{(\nu-2)} \lambda\left(\mathbf{I}+\mathbf{X}_{k} \mathbf{V}_{k} \mathbf{X}_{k}\right)$.

Diferentemente do que ocorre nas demais classes de modelos, a função de verossimilhança marginal $L_{k}(\mathbf{y})$ pode ser obtida de forma analítica na classe dos modelos de regressão linear clássica sem que seja preciso recorrer a métodos de integração numérica. Isso permite a obtenção exata da probabilidade condicionada aos dados y $P\left(M_{k} \mid \mathbf{y}\right)$. Para outras classes de modelos, Raftery (1995) sugere a seguinte aproximação para $L_{k}(\mathbf{y})$ :

$$
\log L_{k}(\mathbf{y}) \approx \log f\left(\mathbf{y} \mid \widehat{\boldsymbol{\theta}_{k}}, M_{k}\right)-\left(d_{k} / 2\right) \log (n),
$$

sendo $\widehat{\boldsymbol{\theta}_{\boldsymbol{k}}}$ o estimador de máxima verossimilhança de $\boldsymbol{\theta}_{\boldsymbol{k}}$, cuja dimensão é $d_{k}$ e $n$ o tamanho amostral. Para os modelos de regressão linear em geral, o estimador de máxima verossimilhança de $\widehat{\boldsymbol{\theta}_{\boldsymbol{k}}}$ pode ser obtido sem dificuldade mesmo que a sua dimensão seja muito grande, entretanto, para modelos não-lineares, o estimador de máxima verossimilhança de $\boldsymbol{\theta}_{\boldsymbol{k}}$ deve ser obtido por meio de métodos iterativos, sendo que a dificuldade de obtenção aumenta a medida que aumenta a dimensão de $\boldsymbol{\theta}_{\boldsymbol{k}}$.

Após a obtenção de $L_{k}(\mathbf{y})$ e $P\left(M_{k} \mid \mathbf{y}\right)$, a próxima etapa envolve a obtenção de $\pi\left(\Delta \mid M_{k}, \mathbf{y}\right)$, a distribuição a posteriori de $\Delta$ para cada modelo de $\mathcal{C}_{\Delta}$. Para os casos em que $\Delta=\beta_{j}$, deve-se obter a distribuição a posteriori de $\beta_{j k}$, ou seja, a distribuição de $\beta_{j}$ sob cada modelo de $\mathcal{C}_{\Delta}$. Recomenda-se que primeiramente seja obtida a distribuição de $\boldsymbol{\beta}_{k}$, ou seja, do vetor de coeficientes de regressão do modelo $M_{k}$. Há duas possibilidades:

(i) Obter $\pi\left(\boldsymbol{\beta}_{k} \mid M_{k}, \mathbf{y}\right)$ via distribuição marginal a posteriori de $\left(\boldsymbol{\beta}_{k}, \sigma^{2}\right)$. Isto é:

$$
\pi\left(\boldsymbol{\beta}_{k} \mid \mathbf{y}\right)=\int_{0}^{\infty} \pi\left(\boldsymbol{\beta}_{k}, \sigma^{2} \mid \mathbf{y}\right) d \sigma^{2},
$$

cujo resultado é $\boldsymbol{\beta}_{k} \mid \mathbf{y} \sim t_{\nu_{*}}\left(\boldsymbol{\mu}_{\boldsymbol{k} *}, \lambda_{*} \mathbf{V}_{k *}\right)$, ou seja, o vetor dos coeficientes de regressão de $M_{k}$ segue distribuição $t$ de Student $\left(p_{k}+1\right)$ dimensional com vetor de locação: 


$$
\boldsymbol{\mu}_{\boldsymbol{k} *}=\left(\mathbf{X}_{k}^{\prime} \mathbf{X}_{k}+\mathbf{V}_{k}^{-1}\right)^{-1}\left(\mathbf{X}_{k}^{\prime} \mathbf{y}+\mathbf{V}^{-1} \boldsymbol{\mu}_{\boldsymbol{k}}\right)
$$

matriz de escala:

$$
\lambda_{*} \mathbf{V}_{k *}=\lambda_{*}\left(\mathbf{X}_{k}^{\prime} \mathbf{X}_{k}+\mathbf{V}_{k}^{-1}\right)^{-1}
$$

e $\nu_{*}$ graus de liberdade, sendo que:

$$
\nu_{*}=n+\nu
$$

e

$$
\lambda_{*}=\frac{1}{\nu_{*}}\left[\nu \lambda+\boldsymbol{\mu}_{\boldsymbol{k}}^{\prime} \mathbf{V}_{k}^{-1} \boldsymbol{\mu}_{\boldsymbol{k}}+\mathbf{y}^{\prime} \mathbf{y}-\left(\mathbf{X}_{k}^{\prime} \mathbf{y}+\mathbf{V}^{-1} \boldsymbol{\mu}_{\boldsymbol{k}}\right)^{\prime}\left(\mathbf{X}_{k}^{\prime} \mathbf{X}_{k}+\mathbf{V}_{k}^{-1}\right)^{-1}\left(\mathbf{X}_{k}^{\prime} \mathbf{y}+\mathbf{V}^{-1} \boldsymbol{\mu}_{\boldsymbol{k}}\right)\right]
$$

(ii) Obter a distribuição a posteriori de $\boldsymbol{\beta}_{k}$ condicionada a $\sigma^{2}, \pi\left(\boldsymbol{\beta}_{k} \mid \sigma^{2}, \mathbf{y}\right)$. Isto é:

$$
\pi\left(\boldsymbol{\beta}_{k} \mid \sigma^{2}, \mathbf{y}\right) \propto L\left(\boldsymbol{\beta}_{k}, \sigma^{2} ; \mathbf{y}\right) \pi\left(\boldsymbol{\beta}_{k} \mid \sigma^{2}\right)
$$

cujo resultado é $\boldsymbol{\beta}_{k} \mid \sigma^{2}, \mathbf{y} \sim N\left(\boldsymbol{\mu}_{k *} ; \sigma^{2} \mathbf{V}_{k *}\right)$, ou seja, o vetor de coeficientes de regressão de $M_{k}$ segue distribuição normal $\left(p_{k}+1\right)$ dimensional condicionada a $\sigma^{2}$ com média $\boldsymbol{\mu}_{\boldsymbol{k} *}$ e matriz de variâncias e covariâncias $\sigma^{2} \mathbf{V}_{k *}$ apresentadas em (i).

Escolhida uma das opções, a análise prossegue e o próximo passo é a obtenção de $\pi\left(\beta_{j k} \mid \mathbf{y}\right)$, ou equivalentemente, $\pi\left(\beta_{j} \mid M_{k}, \mathbf{y}\right)$, que se dá pela obtenção da distribuição marginal de $\beta_{j}$ em relação aos outros parâmetros de $\boldsymbol{\beta}_{k}$. Para a opção (ii), tem-se:

$$
\beta_{j} \mid \sigma^{2}, M_{k}, \mathbf{y} \sim N\left(\mu_{k * j} ; \sigma^{2} V_{k * j j}\right)
$$

em que $\boldsymbol{\mu}_{k * j}$ e $\mathbf{V}_{k * j j}$ correspondem, respectivamente, ao $j$-ésimo elemento de $\boldsymbol{\mu}_{k *}$ e ao $j$ elemento da diagonal principal de $\mathbf{V}_{k *}$.

Viallefont et al. (2001) apresenta a probabilidade

$$
P\left(\beta_{j} \neq 0 \mid \mathbf{y}\right)=\sum_{C_{\Delta}} P\left(M_{k} \mid \mathbf{y}\right)
$$

como alternativa para testar hipótese acerca da significância de $\beta_{j}$. Uma regra convencional para se concluir a respeito do efeito de $X_{1}$, segundo Viallefont et al. (2001) é dizer que não há evidências que comprovem sua significância se $P\left(\beta_{j} \neq 0 \mid \mathbf{y}\right)<50 \%$. Já valores entre $50 \%$ e $75 \%$ indicam fraca evidência, enquanto que valores acima de $75 \%$ até $95 \%$ indicam evidência positiva e valores acima de $95 \%$ indicam uma evidência muito forte. 
Se por outro lado o interesse do pesquisador for a predição de $Y \mid \mathbf{x}_{\mathbf{0}}$, então $\Delta=Y_{0}$ e portanto o termo $\pi\left(\Delta \mid M_{k}, \mathbf{y}\right)$ representa a função densidade preditiva a posteriori de $Y \mid \mathbf{x}_{0}$ sob $M_{k}$, dada por:

$f\left(y_{0} \mid M_{k}, \mathbf{y}\right)=\frac{\Gamma\left(\frac{\nu_{*}+1}{2}\right)}{\Gamma(1 / 2) \Gamma\left(\nu_{*} / 2\right)} \nu_{*}^{\nu_{*} / 2}\left|\lambda_{*}\left(\mathbf{x}_{0}^{\prime} \mathbf{V}_{k *} \mathbf{x}_{0}+1\right)\right|^{-1 / 2}\left[\nu_{*}+\frac{\left(y_{0}-\mathbf{x}_{0}^{\prime} \boldsymbol{\mu}_{k *}\right)^{2}}{\left[\lambda_{*}\left(\mathbf{x}_{0}^{\prime} \mathbf{V}_{k *} \mathbf{x}_{0}+1\right)\right]}\right]^{-\left(\nu_{*}+1\right) / 2}$,

que corresponde a função densidade de uma distribuição $t$ de Student univariada com $\nu_{*}$ graus de liberdade, média $\mathbf{x}_{0}^{\prime} \mu_{k *}$ e variância $\frac{\nu_{*}}{\left(\nu_{*}-2\right)} \lambda_{*}\left(\mathbf{x}_{0}^{\prime} \mathbf{V}_{k *} \mathbf{x}_{0}+1\right)$.

A última etapa do BMA compreende a ponderação de todas as distribuições de $\Delta$ sob os modelos de $\mathcal{C}_{\Delta}$ conforme (4), sendo a média e variância ponderada dadas respectivamente por:

$$
\begin{aligned}
& E(\Delta \mid \mathbf{y})=\sum_{M_{k} \in \mathcal{C}_{\Delta}} E\left(\Delta \mid M_{k}, \mathbf{y}\right) p_{M_{k}}, \\
V(\Delta \mid \mathbf{y})= & \sum_{M_{k} \in \mathcal{C}_{\Delta}} V\left(\Delta \mid M_{k}, \sigma^{2}, \mathbf{y}\right) p_{M_{k}} \\
& +\sum_{M_{k} \in \mathcal{C}_{\Delta}}\left[E\left(\Delta \mid M_{k}, \sigma^{2}, \mathbf{y}\right)-E\left(\Delta \mid \sigma^{2}, \mathbf{y}\right)\right]^{2} p_{M_{k}}
\end{aligned}
$$

Para avaliar o desempenho preditivo do BMA, cada uma das 9000 amostras simuladas foi dividida aleatoriamente em duas partes: a primeira parte contendo (n-25) observações, destinada à aplicação dos critérios de seleção $R^{2}, \bar{R}^{2}, C_{p}$ e $P R E S S$ além da aplicação da ponderação de modelos e a segunda parte contendo 25 observações, utilizada para o cálculo do Logaritmo do Escore Preditivo (LEP). O LEP foi proposto por Good (1952) em seu trabalho de caráter filosófico que teve como objetivo estabelecer as relações entre a Teoria das Probabilidades e a Teoria do Comportamento Racional. Para um modelo qualquer $M$, selecionado por um determinado critério de seleção, o LEP é calculado da seguinte maneira:

$$
L E P=-\sum_{i=1}^{25} \log f\left(y_{0 i} \mid M, \mathbf{y}\right)
$$

em que $f\left(y_{0 i} \mid M, \mathbf{y}\right)$ é o valor da expressão (11) calculado para cada observação simulada $\left(\mathbf{x}_{0 i}, y_{0 i}\right), i=1, \ldots, 25$, enquanto que o LEP da ponderação Bayesiana é dado por:

$$
L E P=-\sum_{i=1}^{25} \log \left\{\sum_{M_{k} \in \mathcal{C}} f\left(y_{0 i} \mid M_{k}, \mathbf{y}\right) P\left(M_{k} \mid \mathbf{y}\right)\right\} \text {. }
$$


Quanto menor é o valor do LEP melhor é considerada a capacidade preditiva do modelo utilizado para seu cálculo. Dessa maneira, o LEP possibilita medir o desempenho preditivo do critério que o selecionou. Como foram simuladas 1000 amostras para cada combinação entre tamanho amostral e cultivar, foram obtidos 1000 valores de LEP para cada um dos critérios de seleção e para a ponderação Bayesiana em cada combinação. Os programas utilizados para a obtenção dos valores do LEP podem ser vistos nos Anexos A e B. 


\section{RESULTADOS E DISCUSSÃO}

As Tabelas 6, 7 e 8 são apresentadas com o propósito de mostrar quão difícil pode ser o processo de escolha de um modelo por meio de critérios de seleção, como por exemplo o Coeficiente de Determinação Múltipla Ajustado, $\bar{R}^{2}$. O problema da incerteza diante da escolha de um modelo foi explorado utilizando os resultados do $\bar{R}^{2}$ pelo fato deste critério ser um dos mais utilizados na estatística aplicada. As respectivas Tabelas 6,7 e 8 contêm os dois melhores ajustes dentre os modelos com $1,2, \ldots, 7$ variáveis explicativas e o ajuste do modelo completo com base nos dados dos cultivares C-111, Piranão e Flint Composto. Nos três conjuntos de dados analisados pode-se observar que os valores de $\bar{R}^{2}$ dos modelos são muito semelhantes, além disso, pode-se observar que os modelos fornecem diferentes estimativas para um mesmo coeficiente de regressão, sendo que as maiores diferenças podem ser observadas entre as estimativas fornecidas pelos modelos ajustados para os dados do cultivar Flint Composto, o qual possui o maior grau de multicolinearidade dentre os três cultivares, com número de condição da matrix $\mathbf{X}^{\prime} \mathbf{X}$ igual a 12826,69.

O fato das maiores variações entre as estimativas de um mesmo coeficiente terem sido observadas justamente no conjunto de dados com maior grau de multicolinearidade é coerente com a observação feita por Hoeting (1994, p.65) de que a indecisão do pesquisador diante da escolha de um modelo pode aumentar a medida que o grau de multicolinearidade aumenta. Leamer (1978, p.92) também faz uma observação nesse sentido, dizendo que a incerteza sobre o modelo a ser escolhido é irrelevante para o processo de inferência dos coeficientes se e somente se suas estimativas forem as mesmas para todos os modelos.

Devido a maior multicolinearidade ter sido observada nos dados do cultivar Flint Composto foi acrescentada, na Tabela 8, uma coluna referente a probabilidade condicionada $P\left(M_{k} \mid \mathbf{y}\right)^{7}$ de cada modelo. Esta informação será utilizada em análise subsequente.

A análise descritiva dos valores de $\bar{R}^{2}$ dos modelos ajustados mostra que:

(i) Para o cultivar C-111, 75\% dos 256 modelos de regressão linear clássica sem interação

\footnotetext{
${ }^{7}$ Calculada através da expressão (10), seção 3.2 .
} 
Tabela 6. Estimativas de mínimos quadrados dos coeficientes de regressão dos modelos selecionados através do critério $\bar{R}^{2}$ - Cultivar C-111

\begin{tabular}{|c|c|c|c|c|c|c|c|c|c|c|}
\hline \multicolumn{11}{|c|}{ Coeficientes } \\
\hline$M_{k}$ & $\beta_{0}$ & $\beta_{1}$ & $\beta_{2}$ & $\beta_{3}$ & $\beta_{4}$ & $\beta_{5}$ & $\beta_{6}$ & $\beta_{7}$ & $\beta_{8}$ & $\bar{R}^{2}$ \\
\hline 1 & 3,50 & 1,25 & & & & & & & & 0,9320 \\
\hline 2 & 5,51 & & 0,14 & & & & & & & 0,7548 \\
\hline 3 & $-0,48$ & 1,11 & & & & 3,96 & & & & 0,9579 \\
\hline 4 & 117,67 & 1,02 & & $-1,56$ & & & & & & 0,9447 \\
\hline 5 & 77,38 & 0,97 & & $-1,06$ & & 3,43 & & & & 0,9630 \\
\hline 6 & $-0,97$ & 1,04 & & & & 4,25 & & & 0,01 & 0,9588 \\
\hline 7 & 151,13 & 0,94 & & $-1,92$ & & 2,81 & $-1,18$ & & & 0,9638 \\
\hline 8 & $-0,55$ & 0,82 & 0,02 & & & 3,41 & & & 0,03 & 0,9629 \\
\hline 9 & 159,01 & 0,89 & & $-1,98$ & & 2,98 & $-1,55$ & & 0,01 & 0,9642 \\
\hline 10 & $-9,68$ & 0,76 & 0,02 & & & 4,25 & & 1,82 & 0,04 & 0,9638 \\
\hline 11 & 278,01 & 0,87 & & $-3,09$ & $-2,23$ & 2,66 & $-2,63$ & & 0,02 & 0,9656 \\
\hline 12 & 475,09 & 0,89 & & $-5,06$ & $-3,77$ & & $-4,66$ & $-2,96$ & 0,02 & 0,9651 \\
\hline 13 & 247,23 & 0,78 & 0,01 & $-2,67$ & $-2,33$ & 2,47 & $-2,45$ & & 0,03 & 0,9656 \\
\hline 14 & 360,09 & 0,88 & & $-3,90$ & $-2,89$ & 1,62 & $-3,47$ & $-1,44$ & 0,02 & 0,9650 \\
\hline 15 & 305,08 & 0,80 & 0,01 & $-3,26$ & $-2,75$ & 1,82 & $-3,03$ & $-0,93$ & 0,03 & 0,9647 \\
\hline
\end{tabular}

que podem ser propostos ao ajuste dos dados possuem $\bar{R}^{2}$ acima de 0,91 ;

(ii) Para o cultivar Piranão, $75 \%$ dos 256 modelos possuem $\bar{R}^{2}$ acima de 0,90 , enquanto que;

(iii) Para o cultivar Flint Composto, $75 \%$ possuem $\bar{R}^{2}$ acima de 0,87 .

Com base nesses resultados, verifica-se uma distribuição bem concentrada dos valores de $\bar{R}^{2}$. Esta concentração pode gerar uma região de incerteza na qual o pesquisador pode ter dificuldades em selecionar um único modelo baseando-se apenas no caráter objetivo dos critérios de seleção.

As diferenças entre as estimativas, mesmo quando não comprovadas estatisticamente, podem representar, na prática, diferentes e importantes decisões, provocando, no responsável pela tomada de decisão, uma indecisão diante do modelo a ser escolhido. Uma alternativa para contornar este problema é obter estimativas para cada coeficiente de regressão por meio de uma ponderação de Bayesiana de modelos, tendo como objetivo a "acomodação" dessas variações entre as estimativas de um mesmo coeficiente.

Por exemplo, para os dados do cultivar Flint Composto, cada coeficiente pode ser estimado pela sua esperança a posteriori, obtida pela ponderação da sua esperança a posteriori sob:

(i) Cada um dos 256 modelos; 
Tabela 7. Estimativas de mínimos quadrados dos coeficientes de regressão dos modelos selecionados através do critério $\bar{R}^{2}$ - Cultivar Piranão

\begin{tabular}{ccccccccccc}
\hline \multicolumn{10}{c}{ Coeficientes } \\
$M_{k}$ & $\beta_{0}$ & $\beta_{1}$ & $\beta_{2}$ & $\beta_{3}$ & $\beta_{4}$ & $\beta_{5}$ & $\beta_{6}$ & $\beta_{7}$ & $\beta_{8}$ & $\bar{R}^{2}$ \\
\hline 1 & 3,82 & 1,06 & & & & & & & & 0,8746 \\
2 & 5,08 & & 0,11 & & & & & & & 0,8132 \\
3 & $-50,10$ & 0,69 & & & 4,40 & & & & & 0,9474 \\
4 & 81,39 & 0,86 & & $-1,12$ & & & & & & 0,9201 \\
5 & $-44,42$ & 0,54 & 0,02 & & 3,93 & & & & & 0,9544 \\
6 & $-17,62$ & 0,69 & & $-0,34$ & 3,68 & & & & & 0,9484 \\
7 & $-34,86$ & 0,48 & 0,03 & & 3,15 & & & & 0,02 & 0,9551 \\
8 & $-21,17$ & 0,54 & 0,02 & $-0,24$ & 3,44 & & & & & 0,9544 \\
9 & $-17,24$ & 0,50 & 0,02 & $-0,20$ & 2,84 & & & & 0,02 & 0,9546 \\
10 & $-39,16$ & 0,47 & 0,03 & & 3,28 & & & 0,56 & 0,03 & 0,9542 \\
11 & $-17,65$ & 0,49 & 0,02 & $-0,20$ & 2,92 & $-0,23$ & & & 0,02 & 0,9532 \\
12 & $-0,16$ & 0,50 & 0,02 & $-0,37$ & 2,69 & & $-0,23$ & & 0,02 & 0,9531 \\
13 & 43,63 & 0,48 & 0,02 & $-0,86$ & 2,55 & $-0,79$ & $-0,84$ & & 0,03 & 0,9524 \\
14 & 276,45 & 0,51 & 0,02 & $-3,12$ & & $-3,20$ & $-3,04$ & $-2,95$ & 0,02 & 0,9523 \\
15 & 157,23 & 0,50 & 0,02 & $-1,97$ & 1,46 & $-2,08$ & $-1,91$ & $-1,64$ & 0,02 & 0,9517 \\
\hline
\end{tabular}

(ii) Os modelos contidos na Tabela 8, ou;

(iii) Os modelos selecionados por outros métodos. Nesse trabalho será utilizado o método Occam's Window.

Tabela 8. Estimativas de mínimos quadrados dos coeficientes de regressão dos modelos selecionados através do critério $\bar{R}^{2}$ - Cultivar Flint Composto

\begin{tabular}{|c|c|c|c|c|c|c|c|c|c|c|c|}
\hline \multirow[b]{2}{*}{$M_{k}$} & \multirow[b]{2}{*}{$\beta_{0}$} & \multirow[b]{2}{*}{$\beta_{1}$} & \multicolumn{4}{|c|}{ Coeficientes } & \multirow[b]{2}{*}{$\beta_{6}$} & \multirow[b]{2}{*}{$\beta_{7}$} & \multirow[b]{2}{*}{$\beta_{8}$} & \multirow[b]{2}{*}{$\bar{R}^{2}$} & \multirow[b]{2}{*}{$P\left(M_{k} \mid \mathbf{y}\right)(\%)$} \\
\hline & & & $\beta_{2}$ & $\beta_{3}$ & $\beta_{4}$ & $\beta_{5}$ & & & & & \\
\hline 1 & 4,27 & 1,07 & & & & & & & & 0,8367 & $<0,00001$ \\
\hline 2 & $-95,78$ & & & & 8,30 & & & & & 0,8099 & $<0,00001$ \\
\hline 3 & $-52,71$ & 0,64 & & & 4,60 & & & & & 0,9566 & 39,36 \\
\hline 4 & 146,04 & 0,66 & & $-2,08$ & & & & & & 0,9207 & 0,0004 \\
\hline 5 & $-49,05$ & 0,71 & & & 4,37 & & & & $-0,02$ & 0,9592 & 14,19 \\
\hline 6 & $-49,78$ & 0,57 & 0,01 & & 4,36 & & & & & 0,9570 & 12,35 \\
\hline 7 & $-49,97$ & 0,71 & & & 3,96 & & 0,47 & & $-0,03$ & 0,9598 & 3,39 \\
\hline 8 & $-35,62$ & 0,78 & & & 3,74 & & & $-1,02$ & 0,04 & 0,9598 & 2,15 \\
\hline 9 & $-29,34$ & 0,72 & 0,01 & & 3,35 & & & $-1,35$ & $-0,03$ & 0,9599 & 2,15 \\
\hline 10 & $-95,00$ & 0,74 & & 0,51 & 4,48 & & 0,76 & & $-0,03$ & 0,9596 & 0,21 \\
\hline 11 & $-113,01$ & 0,67 & 0,01 & 0,74 & 4,53 & & 0,89 & & $-0,03$ & 0,9595 & 0,06 \\
\hline 12 & $-33,70$ & 0,70 & 0,01 & & 3,31 & & 0,26 & $-1,07$ & $-0,03$ & 0,9591 & 0,09 \\
\hline 13 & $-1003,00$ & 0,74 & & 9,57 & 13,53 & 9,25 & 9,93 & 9,07 & $-0,04$ & 0,9605 & $<0,00001$ \\
\hline 14 & $-165,08$ & 0,70 & 0,01 & 1,35 & 4,63 & 1,08 & 1,50 & & $-0,04$ & 0,9589 & 0,0051 \\
\hline 15 & $-1301,00$ & 0,63 & 0,01 & 12,63 & 16,17 & 12,16 & 12,89 & 11,60 & $-0,04$ & 0,9628 & $<0,00001$ \\
\hline
\end{tabular}


Os resultados desta ponderação utilizando os modelos da Tabela 8 podem ser vistos na Tabela 9, onde são apresentadas as estimativas de mínimos quadrados de cada um dos coeficientes de regressão, seus respectivos erros padrão (SE) e seus respectivos $p$-valores, associados ao teste de hipótese acerca da significância das variáveis explicativas.

Além desses resultados, obtidos pelo procedimento clássico de análise de dados, a Tabela 9 apresenta também as estimativas da esperança e variância a posteriori ponderada de cada coeficiente de regressão e a probabilidade $P\left(\beta_{j} \neq 0 \mid \mathbf{y}\right)$ calculada de duas formas: utilizando os modelos da Tabela 8, e utilizando todos os 256 modelos, identificado por $P^{\prime}\left(\beta_{j} \neq 0 \mid \mathbf{y}\right)$. Para $\beta_{5}$ por exemplo, sua esperança, variância a posteriori ponderada e sua probabilidade a posterior $i^{8}$ de ser diferente de zero são dadas respectivamente por:

$$
E\left(\beta_{5} \mid \sigma^{2}, \mathbf{y}\right)=\sum_{k=13}^{15} E\left(\beta_{5} \mid M_{k}, \sigma^{2}, \mathbf{y}\right) p_{M_{k}},
$$

sendo $E\left(\beta_{5} \mid M_{k}, \sigma^{2}, \mathbf{y}\right)$ a média a posteriori de $\beta_{5}$ sob o modelo $M_{k}$ cuja distribuição é dada pela expressão (10),

$$
\begin{aligned}
V\left(\beta_{5} \mid \mathbf{y}\right) & =\sum_{k=13}^{15} V\left(\beta_{5} \mid M_{k}, \sigma^{2}, \mathbf{y}\right) p_{M_{k}} \\
& +\sum_{k=13}^{15}\left[E\left(\beta_{5} \mid M_{k}, \sigma^{2}, \mathbf{y}\right)-E\left(\beta_{5} \mid \sigma^{2}, \mathbf{y}\right)\right]^{2} p_{M_{k}}
\end{aligned}
$$

em que

$$
\begin{gathered}
p_{M_{k}}=\frac{P\left(M_{k} \mid \mathbf{y}\right)}{\sum_{l=13}^{15} P\left(M_{l} \mid \mathbf{y}\right)}, \\
P\left(\beta_{j} \neq 0 \mid \mathbf{y}\right)=\sum_{i=13}^{15} P\left(M_{k} \mid \mathbf{y}\right),
\end{gathered}
$$

e

$$
P^{\prime}\left(\beta_{j} \neq 0 \mid \mathbf{y}\right)=\sum_{M_{k}: \beta_{j} \in M_{k}} P\left(M_{k} \mid \mathbf{y}\right),
$$

sendo que o cálculo de $P^{\prime}\left(\beta_{j} \neq 0 \mid \mathbf{y}\right)$ é feito através do programa apresentado no Anexo C.

Pode-se observar que os resultados apresentados pelas duas formas de análise apresentam algumas concordâncias. Os coeficientes de maior significância segundo a análise clássica são $\beta_{0}$ (intercepto), $\beta_{1}$ e $\beta_{4}$, exatamente os coeficientes que apresentaram as maiores

\footnotetext{
${ }^{8}$ Comentários acerca desta probabilidade podem ser encontrados na seção 2.3.1, p.27.
} 
Tabela 9. Análises clássica e Bayesiana dos dados do cultivar Flint Composto

\begin{tabular}{cccccccc}
\hline \multicolumn{7}{c}{ Análise clássica } & \multicolumn{5}{c}{ BMA } \\
& $\widehat{\beta}$ & $\mathrm{SE}$ & $p$ & $E\left(\beta \mid \sigma^{2}, \mathbf{y}\right)$ & $V\left(\beta \mid \sigma^{2}, \mathbf{y}\right)(\%)$ & $P(\beta \neq 0 \mid \mathbf{y})(\%)$ & $P^{\prime}(\beta \neq 0 \mid \mathbf{y})(\%)$ \\
\hline Intercepto & $-1301,00$ & 580,70 & 0,03 & $-50,31$ & 50,58 & 73,95 & 100 \\
$\beta_{1}$ & 0,63 & 0,11 & $1,07 e^{-5}$ & 0,64 & 0,006 & 73,94 & 100 \\
$\beta_{2}$ & 0,01 & 0,01 & 0,10 & 0,01 & 0,0001 & 14,64 & 22,66 \\
$\beta_{3}$ & 12,63 & 5,80 & 0,03 & 0,12 & 1,39 & 0,26 & 4,97 \\
$\beta_{4}$ & 16,17 & 5,89 & 0,01 & 4,41 & 0,23 & 73,94 & 99,97 \\
$\beta_{5}$ & 12,16 & 5,76 & 0,04 & 1,07 & 0,69 & 0,0051 & 9,17 \\
$\beta_{6}$ & 12,89 & 5,83 & 0,03 & 0,49 & 0,13 & 3,75 & 13,16 \\
$\beta_{7}$ & 11,60 & 5,86 & 0,05 & $-1,17$ & 0,34 & 4,39 & 8,37 \\
$\beta_{8}$ & $-0,04$ & 0,01 & 0,04 & $-0,02$ & 0,0002 & 22,24 & 28,06 \\
\hline
\end{tabular}

probabilidades a posteriori. Todos os demais coeficientes apresentaram $P\left(\beta_{j} \neq 0 \mid \mathbf{y}\right)<0,5$, resultado que, conforme Viallefont et al. (2001) pode indicar a não significância das variáveis associadas a estes coeficientes, enquanto que pela análise clássica, esses coeficientes podem ser considerados significativos pelo fato de seus $p$-valores associados estarem abaixo do valor usualmente utilizado de 0,05 . O coeficiente $\beta_{2}$ foi o único coeficiente a apresentar $p$-valor acima de 0,05, além disso, sua probabilidade a posteriori também indica que não há evidências para considerá-lo significativo.

Levando-se em conta a alta multicolinearidade presente nos dados, algumas variáveis explicativas podem ser irrelevantes à explicação de $Y$, os valores obtidos pelo cálculo de $P\left(\beta_{j} \neq 0 \mid \mathbf{y}\right)$ parecem ser mais coerentes que os resultados obtidos pelos $p$-valores no sentido de identificar com maior eficiência as variáveis mais importantes. Com base na análise clássica, vários modelos poderiam ser propostos ao pesquisador, dentre eles $M_{3}$ e $M_{4}$ (Tabela 8), enquanto que com base na análise Bayesiana pode ser identificado com maior clareza um único modelo:

$$
Y_{i}=-50,31+0,64 X_{1}+4,41 X_{4}
$$

Como já comentado anteriormente, a ponderação poderia ter sido realizada levando-se em conta todos os 256 modelos ou outro grupo de modelos, escolhidos com base em outro método, como por exemplo o Occam's Window (OW). De acordo com Madigan \& Raftery (1994) o Occam's Window é um método eficiente para identificar os modelos que melhor se ajustam aos dados. Os modelos identificados pelo OW podem ser utilizados na ponderação Bayesiana dos coeficientes de regressão evitando com isso que modelos super- 
parametrizados sejam levados em consideração. No OW, o rigor no processo de descarte dos modelos pode ser regulado pelos valores definidos para $a$ e $O_{R}$ (respectivamente primeira e segunda regra do OW) de modo que quanto maior forem $a$ e $O_{R}$ maior será o rigor no processo de descarte. A Tabela 10 apresenta os modelos selecionados pelo OW ${ }^{9}$ simétrico considerando três valores diferentes para a: 5, 20 (sugestão de Madigan \& Raftery (1994)) e 35.

Tabela 10. Modelos selecionados pelo Occam's Window simétrico, executado com diferentes valores de $a$

\begin{tabular}{|c|c|c|c|c|c|c|c|c|c|c|}
\hline \multicolumn{11}{|c|}{ Coeficientes } \\
\hline$M_{k}$ & $\beta_{0}$ & $\beta_{1}$ & $\beta_{2}$ & $\beta_{3}$ & $\beta_{4}$ & $\beta_{5}$ & $\beta_{6}$ & $\beta_{7}$ & $\beta_{8}$ & $P\left(M_{k} \mid \mathbf{y}\right)(\%)$ \\
\hline $1^{(1)(2)(3)}$ & $-52,71$ & 0,64 & & & 4,60 & & & & & 39,36 \\
\hline $2^{(1)(2)(3)}$ & $-49,78$ & 0,57 & 0,01 & & 4,36 & & & & & 12,35 \\
\hline $3^{(1)(2)}$ & $-40,96$ & 0,63 & & $-0,13$ & 4,39 & & & & & 2,00 \\
\hline $4^{(1)(2)}$ & $-53,77$ & 0,63 & & & 4,76 & $-0,68$ & & & & 3,80 \\
\hline $5^{(1)}$ & $-50,67$ & 0,55 & 0,01 & & 4,52 & $-0,82$ & & & & 1,51 \\
\hline $6^{(1)(2)}$ & $-53,58$ & 0,63 & & & 4,40 & & 0,24 & & & 4,75 \\
\hline $7^{(1)}$ & $-50,62$ & 0,55 & 0,01 & & 4,11 & & 0,29 & & & 1,71 \\
\hline $8^{(1)(2)}$ & $-54,10$ & 0,64 & & & 4,66 & & & 0,12 & & 2,48 \\
\hline $9^{(1)(2)(3)}$ & $-49,05$ & 0,71 & & & 4,37 & & & & $-0,02$ & 14,19 \\
\hline $10^{(1)(2)}$ & $-47,99$ & 0,67 & 0,005 & & 4,28 & & & & $-0,02$ & 2,70 \\
\hline $11^{(1)}$ & $-50,11$ & 0,71 & & & 4,54 & $-0,69$ & & & $-0,02$ & 1,45 \\
\hline $12^{(1)(2)}$ & $-49,97$ & 0,71 & & & 3,96 & & 0,47 & & $-0,03$ & 3,39 \\
\hline $13^{(1)(2)}$ & $-35,62$ & 0,78 & & & 3,74 & & & $-1,02$ & $-0,04$ & 2,15 \\
\hline
\end{tabular}

(1) Modelos selecionados pelo OW com $a=35$.

(2) Modelos selecionados pelo OW com $a=20$.

(3) Modelos selecionados pelo OW com $a=5$.

Observa-se que dos 256 modelos, 13 foram selecionados pelo OW simétrico com $a=35$, já pelo OW com $a=20,10$ modelos foram selecionados enquanto que pelo $\mathrm{OW}$ com $a=5$ apenas 3 modelos foram selecionados. A Tabela 11 apresenta as esperanças, as variância e os valores de $P\left(\beta_{j} \neq 0 \mid \mathbf{y}\right)$ para cada coeficiente de regressão obtidos pela ponderação dos modelos selecionados pelos três diferentes valores de $a$.

\footnotetext{
${ }^{9} \mathrm{O}$ programa que executa o OW encontra-se no Anexo C.
} 
Tabela 11. Esperança e variância a posteriori de cada coeficiente obtida pela ponderação dos modelos selecionados pelo OW para cada valor de $a$

\begin{tabular}{|c|c|c|c|c|c|c|c|c|c|}
\hline & \multicolumn{3}{|c|}{$O W_{a=5}$} & \multicolumn{3}{|c|}{$O W_{a=20}$} & \multicolumn{3}{|c|}{$O W_{a}=35$} \\
\hline & $E\left(\beta \mid \sigma^{2}, \mathbf{y}\right)$ & $V\left(\beta \mid \sigma^{2}, \mathbf{y}\right)$ & $P(\beta \neq 0 \mid \mathbf{y})$ & $E\left(\beta \mid \sigma^{2}, \mathbf{y}\right)$ & $V\left(\beta \mid \sigma^{2}, \mathbf{y}\right)$ & $P(\beta \neq 0 \mid \mathbf{y})$ & $E\left(\beta \mid \sigma^{2}, \mathbf{y}\right)$ & $V\left(\beta \mid \sigma^{2}, \mathbf{y}\right)$ & $P(\beta \neq 0 \mid \mathbf{y})$ \\
\hline Intercepto & $-51,29$ & 27,13 & 65,9 & $-50,81$ & 38,47 & 87,17 & $-50,79$ & 37,84 & 91,84 \\
\hline$\beta_{1}$ & 0,63 & 0,05 & 65,9 & 0,64 & 0,005 & 87,17 & 0,64 & 0,006 & 91,84 \\
\hline$\beta_{2}$ & 0,01 & $8,26 e^{-5}$ & 12,35 & 0,009 & $8,55 e^{-5}$ & 15,05 & 0,009 & $8,49 e^{-5}$ & 18,27 \\
\hline$\beta_{3}$ & $\ldots$ & $\ldots$ & 0 & $-0,13$ & 0,01 & 2,0 & $-0,13$ & 0,01 & 2,0 \\
\hline$\beta_{4}$ & 4,49 & 0,16 & 65,9 & 4,45 & 0,20 & 87,17 & 4,45 & 0,20 & 91,84 \\
\hline$\beta_{5}$ & $\ldots$ & $\ldots$ & 0 & $-0,66$ & 0,56 & 3,80 & $-0,69$ & 0,54 & 6,76 \\
\hline$\beta_{6}$ & $\ldots$ & $\ldots$ & 0 & 0,35 & 0,14 & 8,14 & 0,34 & 0,13 & 9,85 \\
\hline$\beta_{7}$ & $\ldots$ & $\ldots$ & 0 & $-0,41$ & 0,62 & 4,63 & $-0,41$ & 0,62 & 4,63 \\
\hline$\beta_{8}$ & $-0,02$ & 0,0002 & 14,19 & $-0,02$ & 0,0002 & 22,43 & $-0,02$ & 0,0002 & 23,88 \\
\hline
\end{tabular}

Alguns aspectos acerca dos resultados da Tabela 11 merecem ser explorados, como por exemplo o fato da taxa de aumento de $P\left(\beta_{j} \neq 0 \mid \mathbf{y}\right)$ em função do aumento de $a$ para os coeficientes $\beta_{0}, \beta_{1}$ e $\beta_{4}$ ser 2,67 vezes maior que a taxa dos demais coeficientes, o que significa que as variáveis mais importantes são logo identificadas para pequenos valores de $a$ e que parece não haver riscos de se concluir acerca da relevância de uma determinada variável quando na realidade as evidências indicariam o contrário se valores maiores para $a$ fossem adotados. Outro resultado observado foi a obtenção de variâncias menores para $\beta_{0}$ e $\beta_{4}$ quando $a=5$, indicando que a variância dos coeficientes pode ser reduzida se a ponderação for realizada com uma quantidade menor de modelos mais plausíveis diante da amostra obtida. Os coeficientes $\beta_{0}, \beta_{1}$ e $\beta_{4}$ foram os que apresentaram os maiores valores de $P(\beta \neq 0 \mid \mathbf{y})$, logo, os modelos propostos ao pesquisador após a ponderação Bayesiana dos coeficientes de regressão com base no OW com $a=5,20$ e 35 são, respectivamente:

$$
\begin{gathered}
Y_{i}=-51,29+0,63 X_{1}+4,49 X_{4}, \\
Y_{i}=-50,81+0,64 X_{1}+4,45 X_{4}
\end{gathered}
$$

$\mathrm{e}$

$$
Y_{i}=-50,79+0,64 X_{1}+4,45 X_{4}
$$

Observando os valores dos coeficientes desses modelos, os valores dos coeficientes do modelo dado pela expressão (12) e as estimativas de $\beta_{0}, \beta_{1}$ e $\beta_{4}$ apresentadas na Tabela 8 pode-se dizer que a aplicação da ponderação Bayesiana permitiu incorporar a incerteza envolvida no processo de escolha de um modelo. 


\subsection{Estudo de Simulação}

A comparação entre o desempenho preditivo da ponderação Bayesiana e o desempenho preditivo dos critérios de seleção $R^{2}, \bar{R}^{2}, C_{p}$ e $P R E S S$ foi realizada com amostras simuladas, obtidas a partir de medidas descritivas dos dados de cada cultivar. A Tabela 12 e a Figura 3 apresentam, respectivamente, as medidas que resumem o comportamento dos valores do número de condição $k^{*}$ e o boxplot dos valores de $k^{*}$ encontrados nas 1000 amostras simuladas para cada uma das 9 combinações entre tamanho amostral e cultivar. Estas combinações são dadas por:

(i) Combinação 1: $\overline{\mathbf{x}}, \mathbf{S}, \widehat{\boldsymbol{\beta}}$ e $Q M R e s$ obtidos a partir dos dados do cultivar C-111, e tamanho amostral $n=50$;

(ii) Combinação 2: $\overline{\mathbf{x}}, \mathbf{S}, \widehat{\boldsymbol{\beta}}$ e $Q M R$ Res obtidos a partir dos dados do cultivar C-111, e tamanho amostral $n=75$;

(iii) Combinação 3: $\overline{\mathbf{x}}, \mathbf{S}, \widehat{\boldsymbol{\beta}}$ e $Q M R$ Res obtidos a partir dos dados do cultivar C-111, e tamanho amostral $n=100$;

(iv) Combinação 4: $\overline{\mathbf{x}}, \mathbf{S}, \widehat{\boldsymbol{\beta}}$ e $Q M R e s$ obtidos a partir dos dados do cultivar Piranão, e tamanho amostral $\mathrm{n}=50$;

(v) Combinação 5: $\overline{\mathbf{x}}, \mathbf{S}, \widehat{\boldsymbol{\beta}}$ e $Q M R e s$ obtidos a partir dos dados do cultivar Piranão, e tamanho amostral $n=75$;

(vi) Combinação 6: $\overline{\mathbf{x}}, \mathbf{S}, \widehat{\boldsymbol{\beta}}$ e $Q M R e s$ obtidos a partir dos dados do cultivar Piranão, e tamanho amostral $n=100$;

(vii) Combinação 7: $\overline{\mathbf{x}}, \mathbf{S}, \widehat{\boldsymbol{\beta}}$ e $Q M$ Res obtidos a partir dos dados do cultivar Flint Composto, e tamanho amostral $n=50$;

(viii) Combinação 8: $\overline{\mathbf{x}}, \mathbf{S}, \widehat{\boldsymbol{\beta}}$ e $Q M R$ Res obtidos a partir dos dados do cultivar Flint Composto, e tamanho amostral $n=75$;

(ix) Combinação 9: $\overline{\mathbf{x}}, \mathbf{S}, \widehat{\boldsymbol{\beta}}$ e $Q M R$ Res obtidos a partir dos dados do cultivar Flint Composto, e tamanho amostral $n=100$; 
Tabela 12. Resumo descritivo para o número de condição $\left(k^{*}\right)$ das amostras geradas para cada combinação tamanho amostral e cultivar

\begin{tabular}{cccccccccc}
\hline Estatística & \multicolumn{3}{c}{ C-111 } & \multicolumn{3}{c}{ Piranão } & \multicolumn{3}{c}{ F. Composto } \\
& 50 & 75 & 100 & 50 & 75 & 100 & 50 & 75 & 100 \\
\hline Mínimo & 171,9 & 164,1 & 191,5 & 598,8 & 545,9 & 611,4 & 4262,0 & 5657,0 & 6808,0 \\
1-Quartil & 378,0 & 374,1 & 367,2 & 1186,0 & 1164,0 & 1152,0 & 12050,0 & 12120,0 & 11960,0 \\
Mediana & 463,3 & 440,8 & 427,7 & 1448,0 & 1366,0 & 1334,0 & 14970,0 & 14130,0 & 13860,0 \\
Média & 491,1 & 453,2 & 435,7 & 1526,0 & 1411,0 & 1364,0 & 15810,0 & 14660,0 & 14150,0 \\
3o-Quartil & 572,5 & 518,5 & 490,3 & 1795,0 & 1621,0 & 1540,0 & 18450,0 & 16810,0 & 16010,0 \\
Máximo & 1367,0 & 929,8 & 917,7 & 4120,0 & 2952,0 & 2802,0 & 42100,0 & 29590,0 & 29120,0 \\
Desvio-Padrão & 163,1 & 113,5 & 94,6 & 494,3 & 352,8 & 299,7 & 5325,5 & 3676,1 & 3105,5 \\
C.V. (em \%) & 33,2 & 25,0 & 21,7 & 32,3 & 25,0 & 21,9 & 33,6 & 25,0 & 21,9 \\
Combinação & 1 & 2 & 3 & 4 & 5 & 6 & 7 & 8 & 9 \\
\hline
\end{tabular}

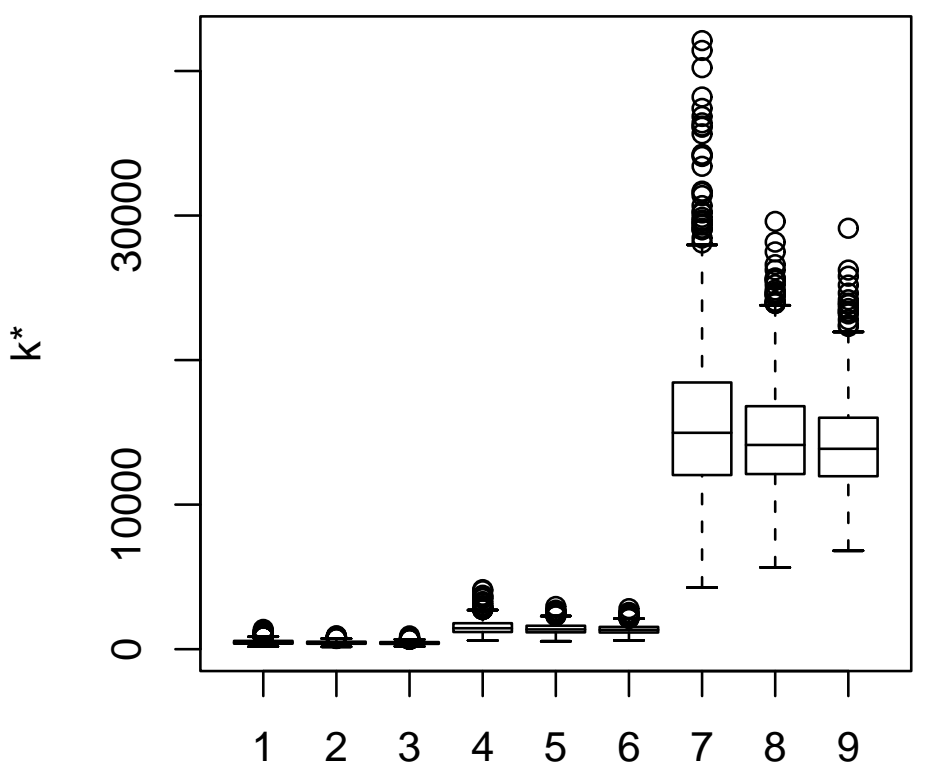

Combinação

Figura 3 - Boxplot para o número de condição das amostras simuladas para cada combinação entre cultivar e tamanho amostral 
As 9000 amostras produziram uma amplitude considerável dos valores de $k$, propiciando uma boa cobertura para as conclusões acerca do dsempenho preditivo do BMA.

As Tabelas 13, 14 e 15 apresentam os resumos descritivos dos valores do LEP para cada uma das combinações. Esses resultados são representados graficamente através da Figura 4, que mostra o comportamento do Logaritmo do Escore Preditivo (LEP) de cada metodologia em função do grau de multicolinearidade e do tamanho amostral. Os resultados empíricos mostram que, para as amostras de tamanho 50, o desempenho preditivo do BMA parece melhorar a medida que o grau de multicolinearidade dos dados aumenta (1a), enquanto que para as amostras de tamanho 75 e 100, o desempenho preditivo dos critérios de seleção se equipararam com o desempenho do BMA (1b e 1c). O mesmo comportamento pode ser observado fixando-se o grau de multicolinearidade e variando o tamanho amostral (2a, $2 \mathrm{~b}$ e $2 \mathrm{c})$.

Tabela 13. Resumo dos valores do LEP nas amostras simuladas (cultivar C-111)

\begin{tabular}{ccccccccc}
\hline$n$ & Metodologia & Mínimo & $1^{0}$ Quartil & Mediana & Média & $3^{0}$ Quartil & Máximo & Variância \\
\hline \multirow{4}{*}{50} & $B M A$ & 42,46 & 51,75 & 54,57 & 55,07 & 57,60 & 89,05 & 26,83 \\
& $R^{2}$ & 41,29 & 51,41 & 55,09 & 55,97 & 59,11 & 90,31 & 40,87 \\
& $\bar{R}^{2}$ & 40,99 & 51,98 & 55,91 & 57,03 & 61,03 & 94,27 & 51,40 \\
& $P R E S S$ & 41,05 & 51,89 & 55,83 & 56,97 & 60,98 & 94,27 & 50,82 \\
& $C_{p}$ & 40,99 & 52,40 & 56,24 & 57,33 & 61,12 & 90,06 & 49,73 \\
& $B M A$ & 40,29 & 49,75 & 52,33 & 52,67 & 55,10 & 70,81 & 17,39 \\
75 & $R^{2}$ & 39,22 & 49,13 & 51,64 & 52,13 & 54,50 & 74,44 & 19,62 \\
& $\bar{R}^{2}$ & 39,73 & 49,34 & 52,00 & 52,58 & 55,20 & 74,17 & 21,85 \\
& $P R E S S$ & 39,77 & 49,30 & 52,04 & 52,59 & 55,24 & 74,17 & 22,12 \\
& $C_{p}$ & 39,99 & 49,62 & 52,30 & 52,98 & 55,56 & 75,15 & 23,99 \\
& $B M A$ & 41,82 & 48,79 & 51,30 & 51,50 & 53,87 & 77,32 & 15,71 \\
& $R^{2}$ & 39,94 & 47,81 & 50,25 & 50,62 & 52,99 & 72,70 & 16,62 \\
& $\bar{R}^{2}$ & 39,87 & 47,97 & 50,60 & 50,87 & 53,48 & 74,69 & 17,80 \\
& $P R E S S$ & 39,87 & 47,94 & 50,58 & 50,87 & 53,45 & 74,69 & 17,78 \\
& $C_{p}$ & 39,87 & 48,15 & 50,86 & 51,14 & 53,61 & 81,82 & 18,64 \\
\hline
\end{tabular}


Tabela 14. Resumo dos valores do LEP nas amostras simuladas (cultivar Piranão)

\begin{tabular}{ccccccccc}
\hline$n$ & Metodologia & Mínimo & $1^{0}$ Quartil & Mediana & Média & $3^{0}$ Quartil & Máximo & Variância \\
\hline \multirow{4}{*}{50} & $B M A$ & 39,55 & 49,26 & 52,05 & 52,92 & 56,02 & 88,83 & 31,31 \\
& $R^{2}$ & 39,94 & 49,80 & 53,49 & 54,21 & 57,57 & 98,62 & 39,32 \\
& $\bar{R}^{2}$ & 39,54 & 50,25 & 54,19 & 55,30 & 59,05 & 102,30 & 54,59 \\
& $P R E S S$ & 39,35 & 49,97 & 54,07 & 55,20 & 58,86 & 102,30 & 54,66 \\
& $C_{p}$ & 39,35 & 50,17 & 54,40 & 55,54 & 59,22 & 98,80 & 57,67 \\
& $B M A$ & 38,71 & 47,32 & 49,98 & 50,25 & 52,53 & 66,99 & 16,32 \\
& $R^{2}$ & 37,38 & 47,44 & 50,01 & 50,49 & 52,91 & 70,37 & 19,70 \\
& $\bar{R}^{2}$ & 37,76 & 47,61 & 50,29 & 50,80 & 53,33 & 70,64 & 22,21 \\
& $P R E S S$ & 37,76 & 47,72 & 50,34 & 50,83 & 53,25 & 70,64 & 21,95 \\
& $C_{p}$ & 37,85 & 47,72 & 50,45 & 50,91 & 53,42 & 70,64 & 22,23 \\
& $B M A$ & 39,59 & 46,40 & 48,95 & 49,11 & 51,32 & 64,63 & 14,68 \\
& $R^{2}$ & 38,33 & 46,33 & 48,89 & 49,17 & 51,68 & 70,65 & 17,03 \\
& $\bar{R}^{2}$ & 38,33 & 46,42 & 49,11 & 49,40 & 51,95 & 72,72 & 18,16 \\
& $P R E S S$ & 38,33 & 46,44 & 49,18 & 49,38 & 51,89 & 72,72 & 17,88 \\
& $C_{p}$ & 38,85 & 46,52 & 49,42 & 49,59 & 52,26 & 72,72 & 18,30 \\
\hline
\end{tabular}

Tabela 15. Resumo dos valores do LEP nas amostras simuladas (cultivar Flint Composto)

\begin{tabular}{ccccccccc}
\hline$n$ & Metodologia & Mínimo & $1^{0}$ Quartil & Mediana & Média & $3^{0}$ Quartil & Máximo & Variância \\
\hline \multirow{4}{*}{50} & $B M A$ & 36,84 & 45,36 & 48,03 & 48,82 & 51,37 & 82,50 & 27,69 \\
& $R^{2}$ & 38,32 & 48,85 & 52,20 & 53,30 & 57,21 & 81,44 & 38,88 \\
& $\bar{R}^{2}$ & 35,30 & 48,77 & 53,34 & 53,81 & 58,01 & 89,94 & 50,88 \\
& $P R E S S$ & 35,30 & 48,49 & 53,30 & 53,75 & 58,06 & 89,94 & 52,75 \\
& $C_{p}$ & 36,93 & 47,04 & 51,98 & 53,00 & 58,01 & 93,95 & 60,03 \\
& $B M A$ & 37,52 & 44,02 & 46,28 & 46,76 & 49,12 & 69,66 & 15,91 \\
& $R^{2}$ & 36,24 & 45,29 & 47,20 & 47,35 & 49,28 & 70,45 & 10,70 \\
& $\bar{R}^{2}$ & 35,07 & 45,50 & 47,40 & 47,65 & 49,74 & 74,73 & 12,45 \\
& $P R E S S$ & 35,55 & 45,49 & 47,10 & 47,63 & 49,67 & 72,21 & 12,21 \\
& $C_{p}$ & 34,59 & 45,76 & 47,83 & 48,18 & 50,39 & 74,73 & 16,67 \\
& $B M A$ & 35,06 & 43,00 & 45,48 & 45,74 & 48,07 & 67,49 & 14,91 \\
& $R^{2}$ & 36,01 & 43,26 & 45,20 & 45,25 & 47,13 & 60,61 & 8,56 \\
$\bar{R}^{2}$ & 35,96 & 43,39 & 45,34 & 45,38 & 47,21 & 63,14 & 9,22 \\
& $P R E S S$ & 35,96 & 43,39 & 45,34 & 45,39 & 47,21 & 63,14 & 9,36 \\
& $C_{p}$ & 36,01 & 43,60 & 45,66 & 45,74 & 47,56 & 69,94 & 11,37 \\
\hline
\end{tabular}



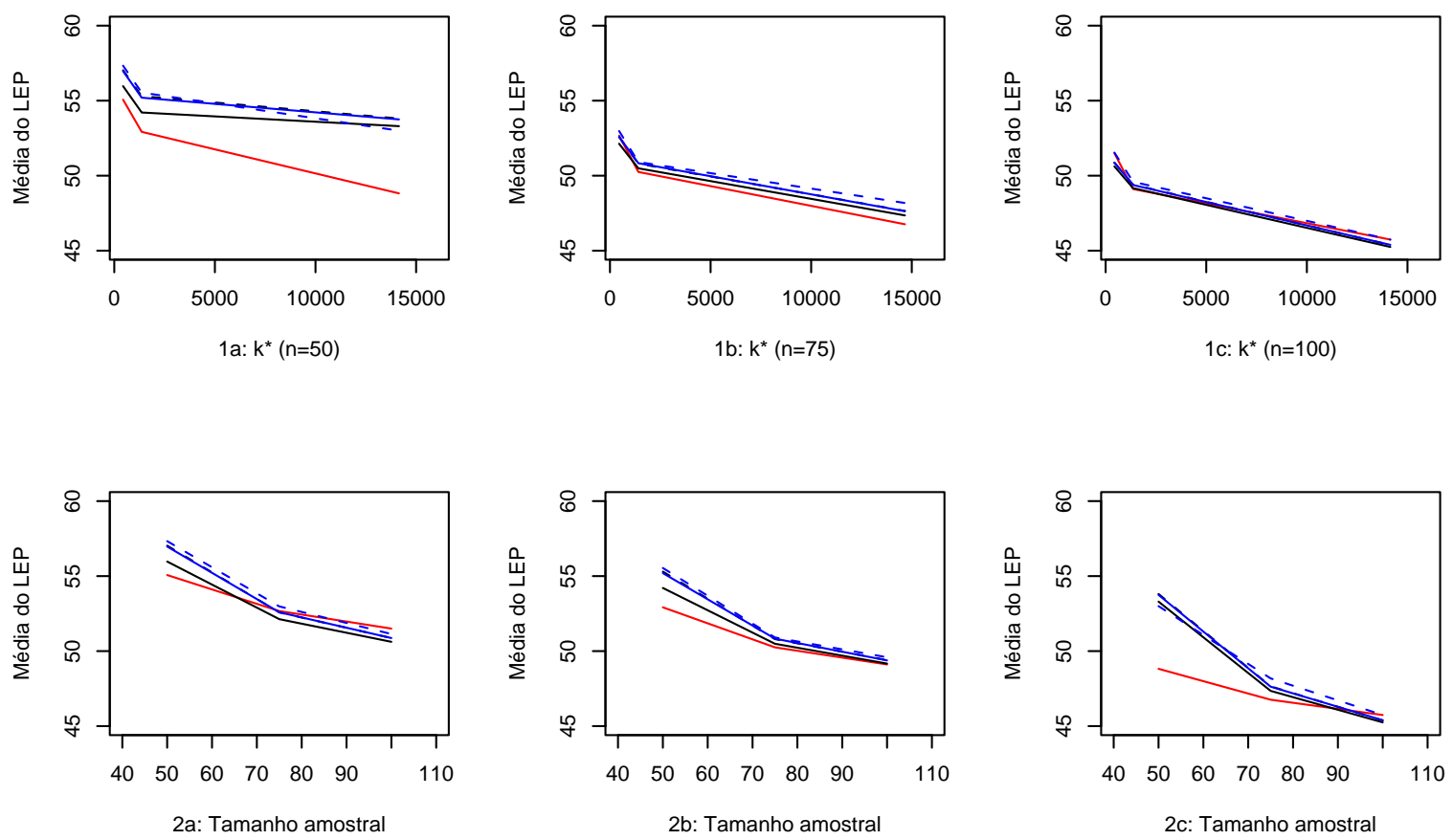

Figura 4 - Comportamento da média do Logaritmo do Escore Preditivo da metodologia BMA (vermelho) e dos critérios: $R^{2}$ (preto), $\bar{R}^{2}$ (preto tracejado), PRESS (azul) e $C_{p}$ (azul Tracejado) 


\section{CONCLUSÕES}

A aplicação da metodologia de ponderação de modelos sob enfoque Bayesiano para a análise do conjunto de dados do cultivar Flint Composto permitiu que incerteza diante da escolha de um modelo fosse de fato incorporada. A aplicação também mostrou que o processo de seleção dos melhores modelos a serem levados em conta na ponderação também pode ser realizado utilizando critérios usuais de seleção, como por exemplo o $\bar{R}^{2}$, pois ao contrário do Occam's Window que precisa ser programado, os critérios usuais de seleção estão disponíveis para uso na maioria dos softwares estatísticos.

Com relação ao desempenho preditivo da ponderação Bayesiana, os resultados empíricos indicaram que esta metodologia apresenta desempenho semelhante aos métodos usuais de seleção de modelos nas situações de multicolinearidade exploradas neste trabalho.

Pretende-se, futuramente, pesquisar alternativas que permitam aprimorar o processo de descarte de modelos promovido pelo Occam's Window (OW). Seria interessante incorporar, na execução do OW, as conseqüências políticas e gerências causadas pela inclusão de uma específica variável. Embora o OW utilize, durante sua execução, a probabilidade a posteriori de cada modelo condicionada aos dados, $P\left(M_{k} \mid \mathbf{y}\right)$, cuja informação subjetiva do pesquisador a respeito de cada modelo é levada em conta no seu cálculo, seria interessante incrementar o OW com informações acerca do custo operacional de cada variável e as implicações causadas pela inclusão dessas no modelo final. 


\section{REFERÊNCIAS BIBLIOGRÁFICAS}

AKAIKE, H. Information theory and an extension of the maximum likelihood principle. In: INTERNATIONAL SYMPOSIUM OF INFORMATION THEORY, 2., Budapest, 1973. Proceedings. Budapest: Akademiai Kiàido, 1973. p.267-281.

BEATON, A.E. The use of special matrix operators in statistical calculus, Princeton, New Jersey. Education Testing Service, 1964. 1v. (Res. Bull RB, 64-51).

BUCKLAND, S.T.; BURNHAM, K.P.; AUGUSTIN, N.H. Model selection: An integral part of inference. Biometrics, v.53, n.2, p.603-618, Jun. 1997.

CANDOLO, C. A incorporação da incerteza devido à escolha de modelos na inferência estatística com aplicação em modelos de regressão linear. Piracicaba, 2001. 80p. Tese(Doutorado) - Escola Superior de Agricultura "Luiz de Queiroz", Universidade de São Paulo.

CANDOLO, C. Um estudo de simulação considerando a incorporação da incerteza na seleção de modelos em regressão linear. Revista de Matemática e Estatística, v.20, n.2, p.111-126, 2004.

CHATTERJEE, S.; PRICE, B. Regression analysis by example. New York: John Wiley, 1977. 228p.

EFROYMSON, M.A. Multiple regression analysis. Mathematical methods for digital computers. Edit. A. Ralston; A.S. Wiley. (Ed). New York; Wiley, 1960. 1v

FONTES, L.S.; ALMEIDA FILHO, A.J.de; ARTHUR, V. Danos causados por Sitophilus Oryzae (Linné, 1763) e Sitophilus Zeanais Motschulsky. 1855(Coleoptera: Curculionidal) em cultivares de arroz (Oryza Sativa L.). Arquivos do Instituto Biológico, v.70, n.3, p.303-307, 2003. 
FURNIVAL, G.M. All possible regressions with less computation. Technometrics, v.13, p.403-408, 1971.

FURNIVAL, G.M.; WILSON, R.W. Regression by leaps and bounds. Technometrics, v.16, p.499-512, 1974.

GALLO, D. ;NAKANO, O.; SILVEIRA NETO, S. et al.Manual de entomologia agrícola. São Paulo: Agronômica Ceres, 1988. 649p.

GARSIDE, M.J. The best subset in multiple regression analysis. Applied Statistics, v.14, n.2, p.196-200, 1965.

GELFAND, A.E.; GHOSH, S.K. Model choice: a minimum poeteriori predictive loss approach. Biometrika, v.85, n.1, p.1-11, 1998.

GEORGE, E.I.; McCULLOCH, R.E. Variable selection via gibbs sampling. Journal of the American Statistical Association, v.88, n.423, p.881-889, Sep. 1993.

GOOD, I.J. Rational decisions. Journal of the Royal Statistical Society, v.14, n.1, p.107$114,1952$.

HOCKING, R.R. The analysis and selection of variables in linear regression. Biometrics, v.32, n.1, p.1-49, Mar. 1976.

HOETING, J.A. Accounting for model uncertainty in linear regression. Washington, 1994. 170p. Thesis(Ph.D.) - University of Washington.

LAUD, P.W.; IBRAHIM, J.G. Predictive specfication of priori model probabilities in variable selection. Biometrika, v.83, n.2, p.267-274, Jun. 1996.

LEAMER, E.E. Specification searches. New York: John Wiley, 1978. 370p.

LEE III, H.K.H. Model selection and model averaging for neural networks. Pittsburg, 1999. 113p. Thesis(Ph.D.) - Carnegie Mellon University.

LYLE, P. Regression analysis of production costs and factory operations. New York: Publishing, 1957. 204p. 
MADIGAN, D.; RAFTERY, A.E. Model selection and accounting for model uncertainty in graphical models using Occam's Window. Journal of the American Statistical Association, v.89, n.428, p.1535-1546, Dec. 1994.

MADIGAN, D.; YORK, J. Bayesian graphical models for discrete data. International Statistical Review, v.63, p.215-232, 1995.

MATSUO, T. O uso da regressão de cumeeira em experimentos agronômicos. Piracicaba, 1986. 89p. Dissertação(Mestrado) - Escola Superior de Agricultura "Luiz de Queiroz", Universidade de São Paulo.

MONTGOMERY, D.C.; PECK, E.A. Introduction to linear regression analysis. New York: John Wiley, 1992. 527p.

NELDER, J.A.; WEDDERBURN, R.W.M. Generalized linear models. Journal of the Royal Statistical Society, v.135, n.3, p.370-384, 1972.

NETER, J.; WASSERMAN, W.; KUTNER, M.H. Applied linear regression models. Homewood: Irwin, 1983. 547p.

NEWTON, R.G.; SPURRELL, D.J. A development of multiple regression for the analysis of routine data. Applied Statistics, v.16, n.1, p.51-65, 1967.

RAFTERY, A.E. Bayesian model selection in social research. Sociological Methodology, v.25, p.111-163, 1995.

RAFTERY, A.E.; MADIGAN, D.; HOETING, J.A. Bayesian model averaging for linear regression models. Journal of the American Statistical Association, v.92, n.437, p.179-191, Mar. 1997.

RAO, P. Some notes on misspecification in multiple regressions. The American Statistician, v.25, n.5, p.37-39, Dec. 1971.

R FUNDATION FOR STATISTICAL COMPUTING. R 2.0.1, 2004. Disponível em: $<$ http://www.cran.r-project.org $>$.

SCHWARZ, G. Estimating the dimension of a model. The Annals of Statistics, v.6, n.2, p.461-464, Mar. 1978. 
SNEDECOR, W.G. Statistical methods. Ames: Iowa State College Press, 1956. 534p.

TVERSKY, A. Assessing uncertainty. Journal of the Royal Statistical Society, v.36, n.2, p.148-159, 1974.

VIALLEFONT, V.; RAFTERY, A.E.; RICHARDSON, S. Variable selection and bayesian model averaging in case-control studies. Statistical in Medicine, v.20, p.3215-3230, Mar. 2001.

WETHERILL, G.B.; DUNCOMBE, P.; KENWARD, M.; et al. Regression analysis with applications. London: Chapman \& Hall, 1986. 311p. 
ANEXOS 
ANEXO A - Programa em $R$ v. 2.0.1 utilizado para obter o Logaritmo do Escore Preditivo (LEP) dos critétios de seleção de modelos.

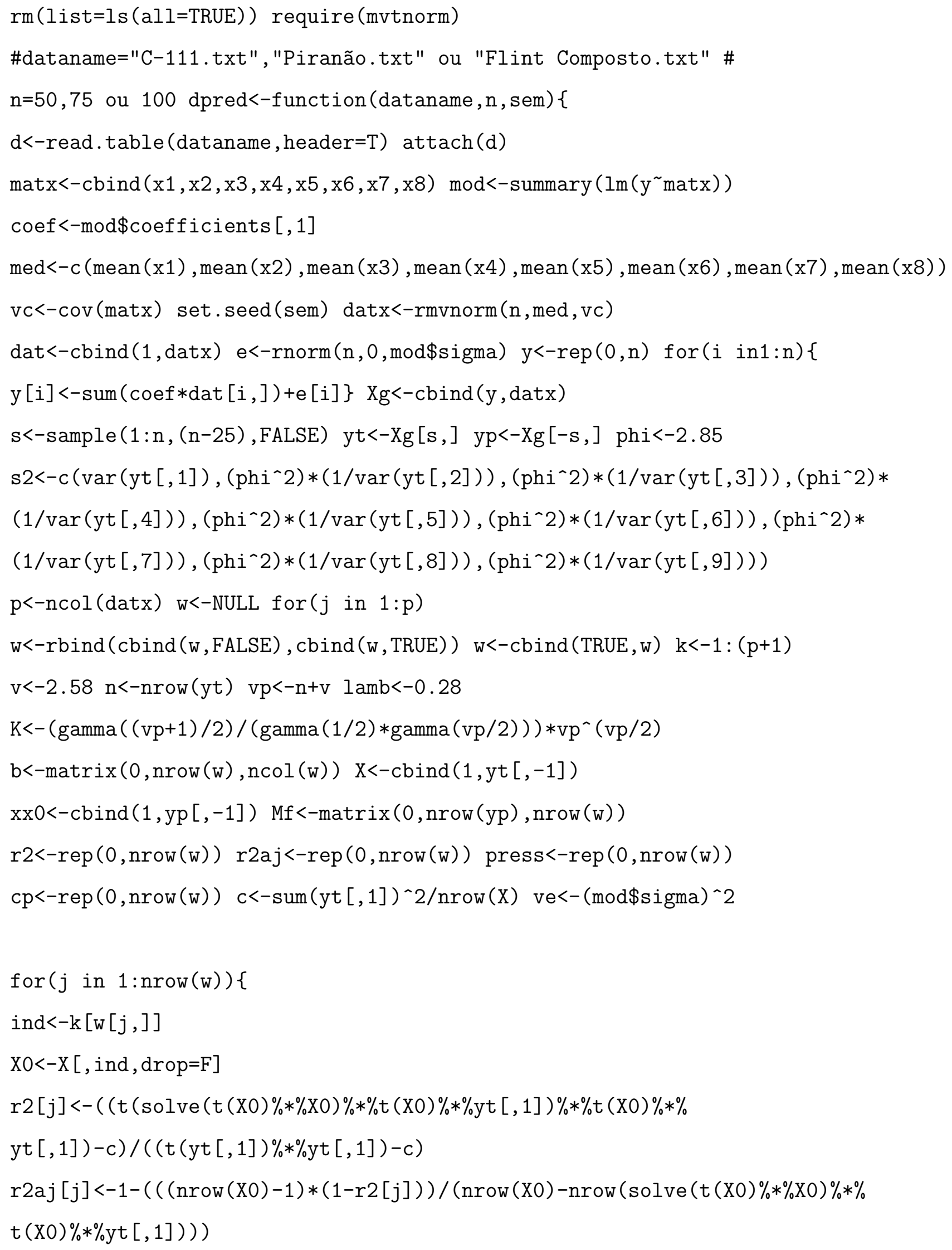




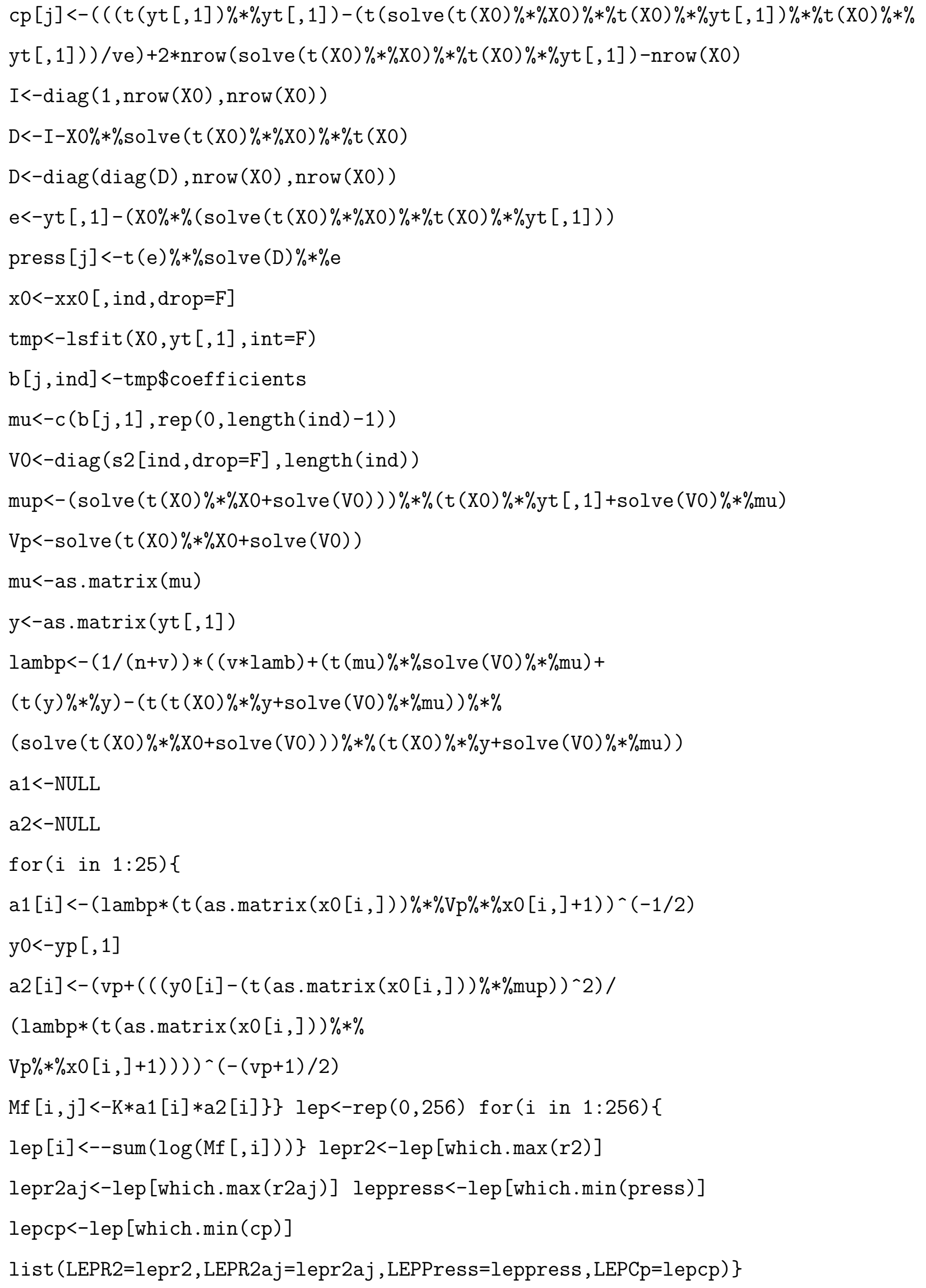




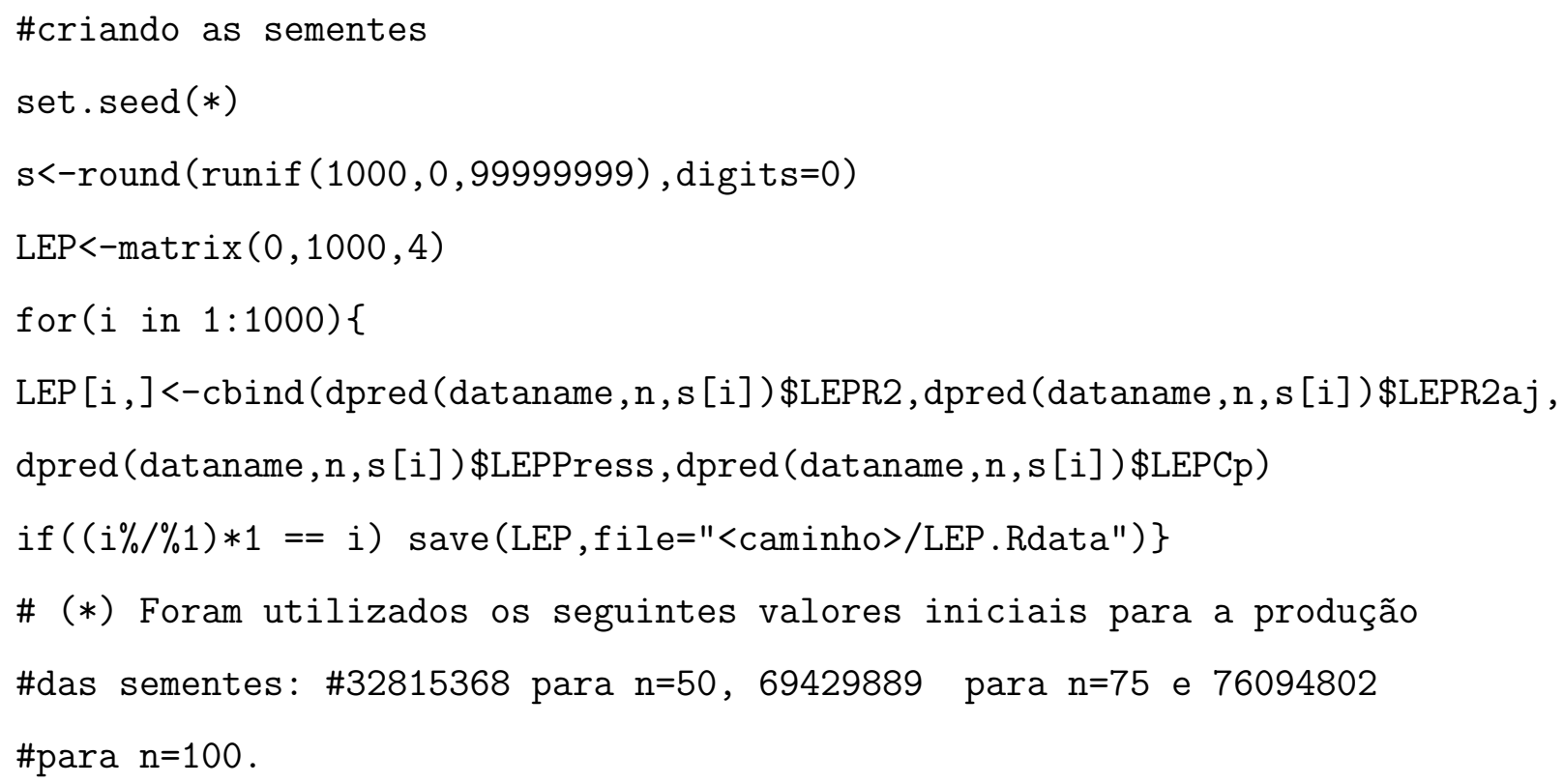


ANEXO B - Programa em $R$ v. 2.0.1 utilizado para obter o Logaritmo do Escore Preditivo (LEP) da ponderação Bayesiana de modelos.

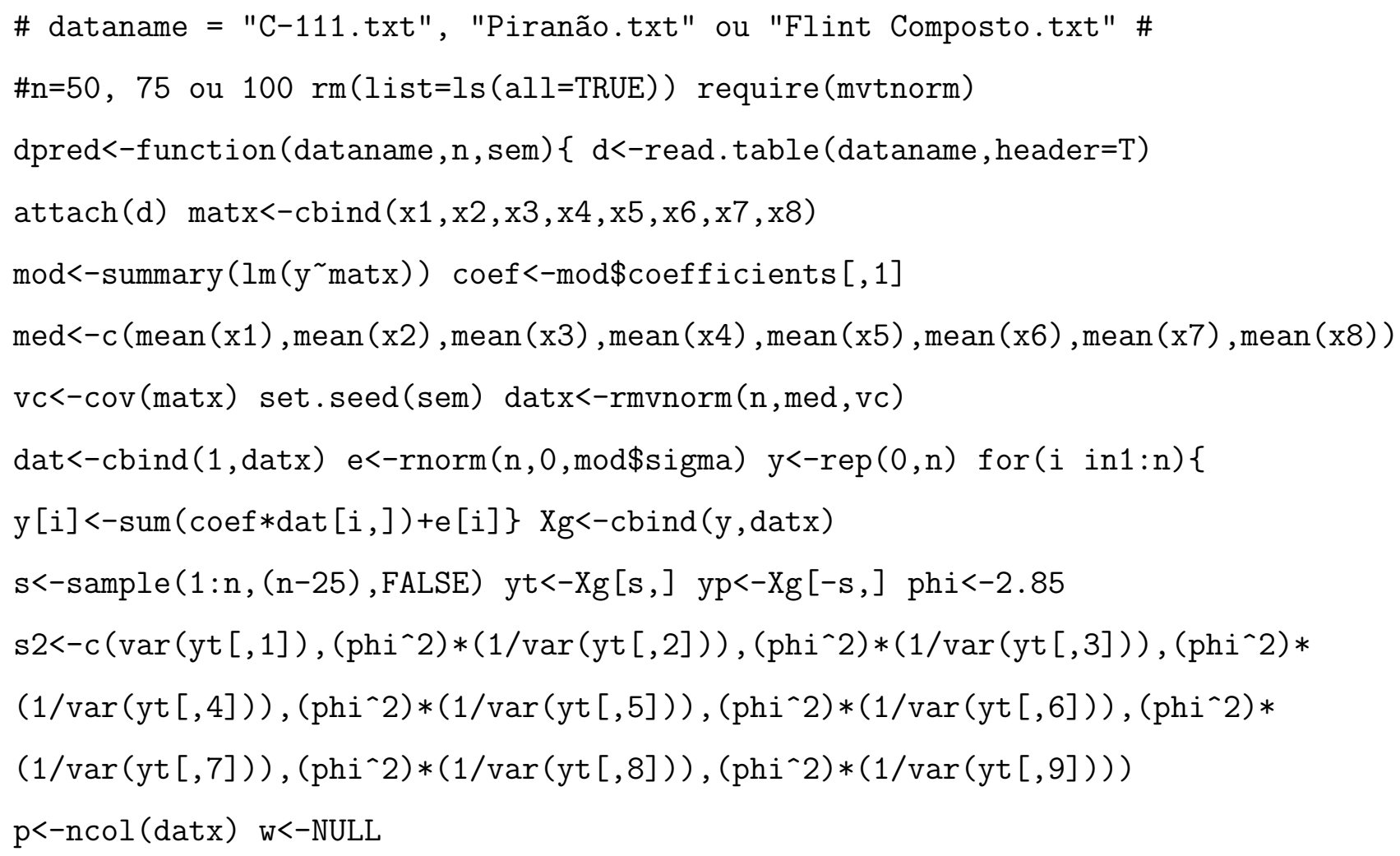




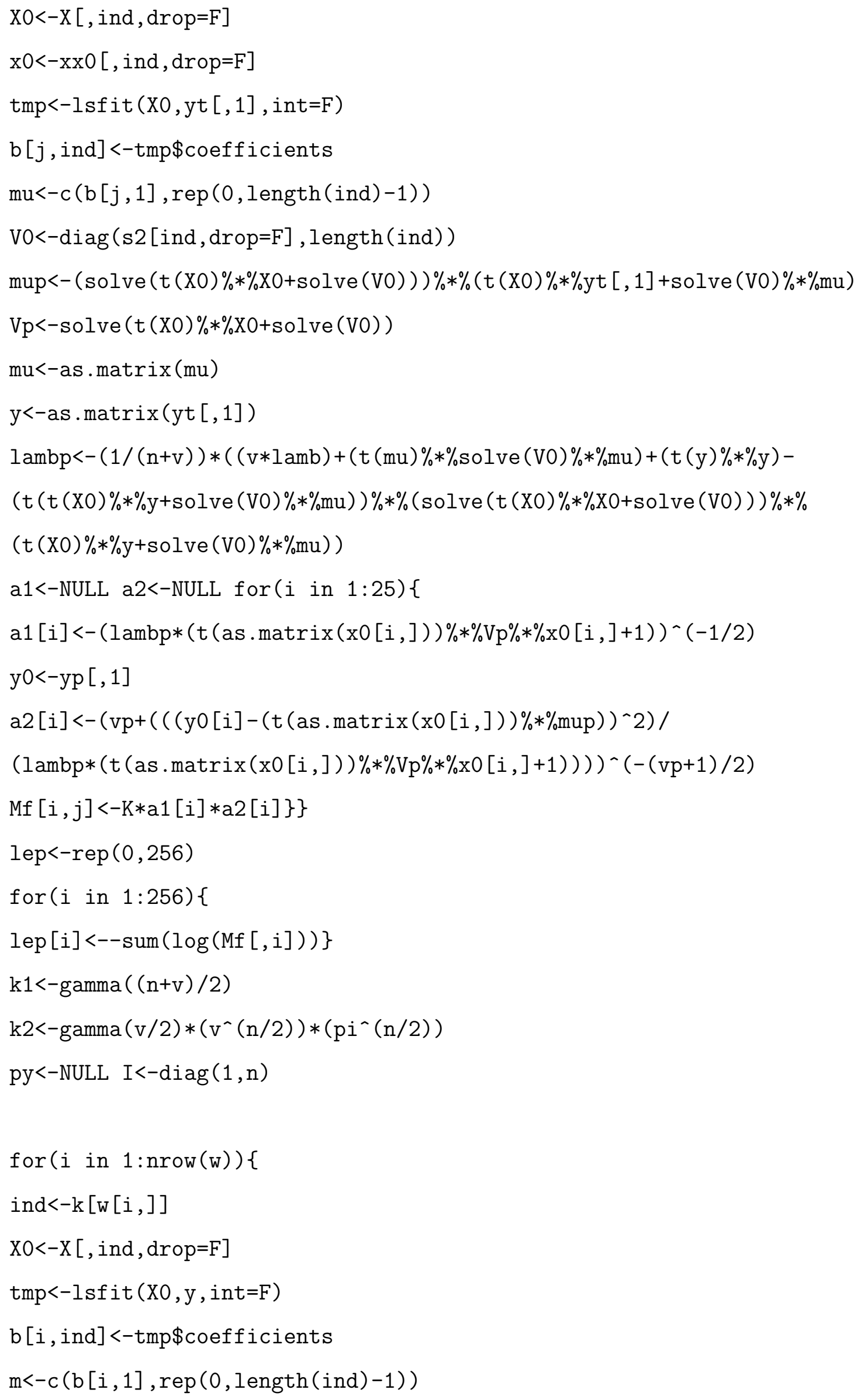




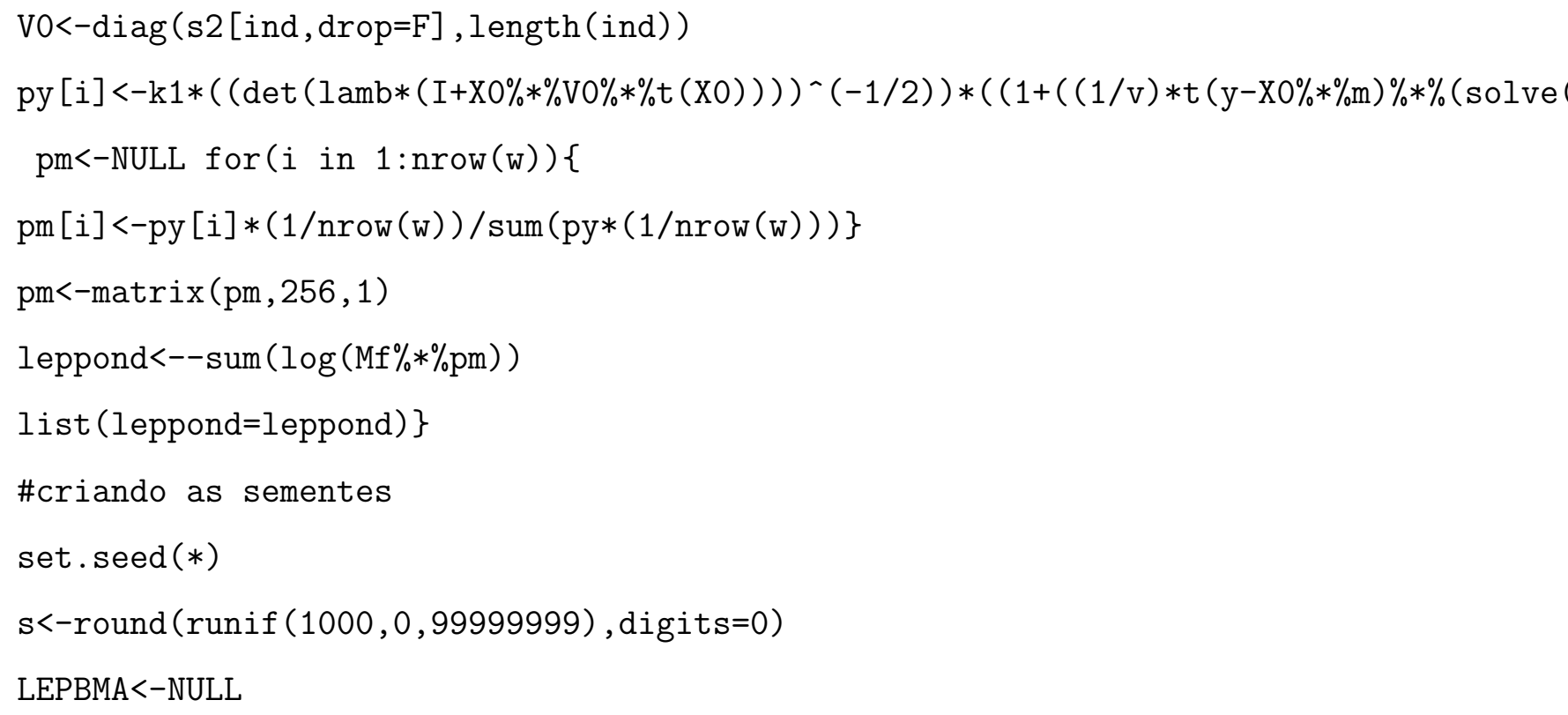


ANEXO C - Programa em $R$ v. 2.0.1 utilizado para executar o Occam's Window e calcular $P\left(\beta_{j} \neq 0 \mid \mathbf{y}\right)$

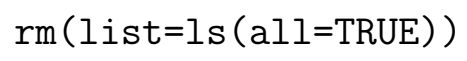




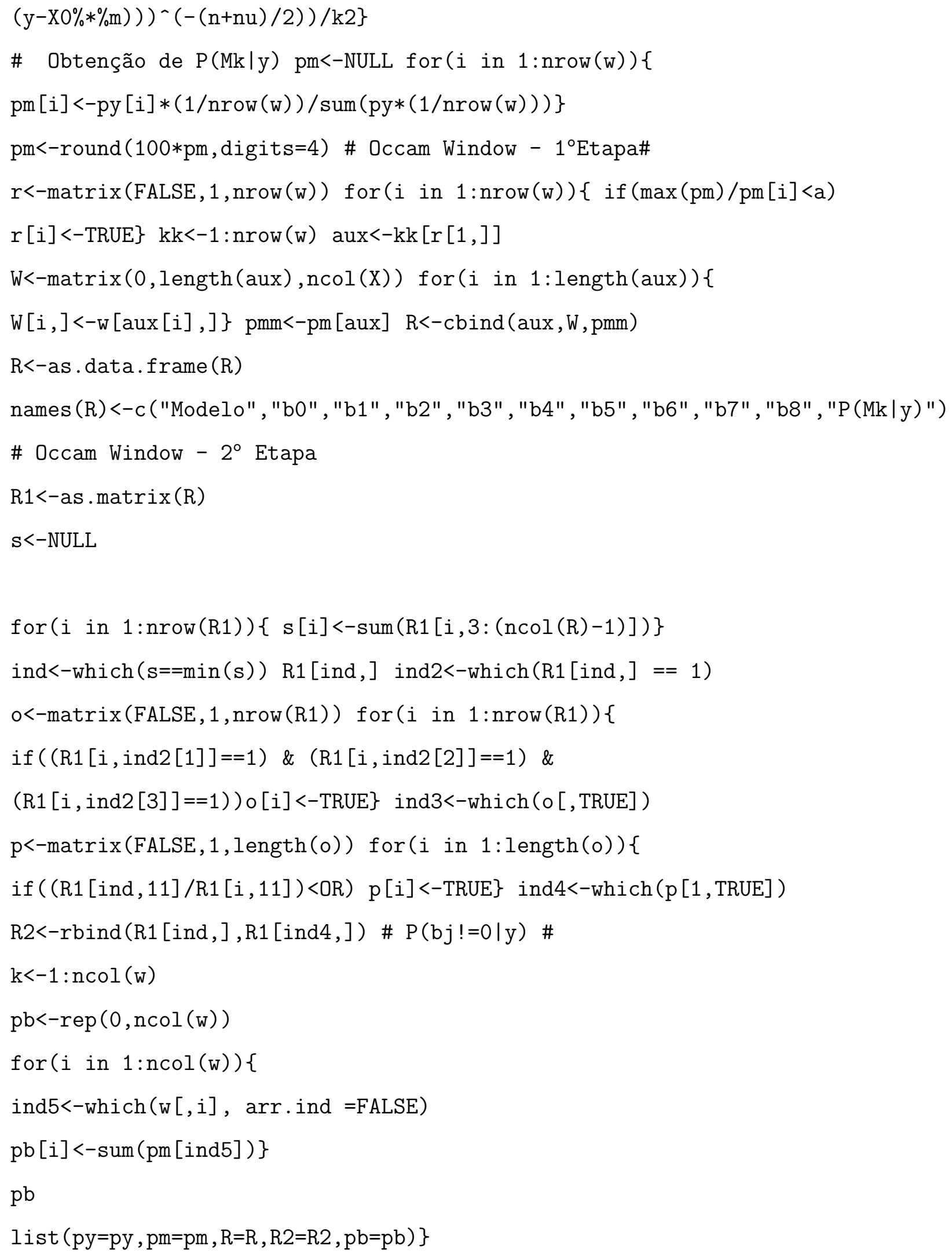

